\title{
PROPOSTA DE AMOSTRAGEM PADRONIZADA PARA MACRO- VESTÍGIOS BIOARQUEOLÓGICOS: ANTRACOLOGIA, ARQUEOBOTÂNICA, ZOOARQUEOLOGIA
}

\author{
Rita Scheel-Ybert* \\ Daniela Klökler** \\ Maria Dulce Gaspar*** \\ Levy Figuti****
}

\begin{abstract}
SCHEEL-YBERT, R.; KLÖKLER, D.; GASPAR, M.D.; FIGUTI, L. Proposta de amostragem padronizada para macro-vestígios bioarqueológicos: antracologia, arqueobotânica, zooarqueologia. Rev. do Museu de Arqueologia e Etnologia, São Paulo, 15-16: 139-163, 2005-2006.
\end{abstract}

RESUMO: Este artigo tem por objetivo alertar para a importância dos estudos de macro-vestígios bioarqueológicos de origem vegetal e animal. Nele é estabelecido um protocolo de amostragem que visa atender às necessidades da pesquisa arqueológica no campo e conduzir a uma coleta sistematizada de restos vegetais, para estudos de antracologia e arqueobotânica, e de restos faunísticos, para estudos de zooarquelogia. Esta estratégia de amostragem visa construir coleções que conduzam à obtenção de dados comparáveis, em sítios diferentes, no que se refere a paleoambiente, sistema de subsistência, território de exploração e interação entre o domínio social e ambiental.

UNITERMOS: Arqueologia - Antracologia - Zooarqueologia - Amostragem Metodologia.

\section{Introdução}

A ciência depende de amostragem, pois o conhecimento científico é produzido mediante investigações de porções limitadas do universo

(*) Museu Nacional, Universidade Federal do Rio de Janeiro-UFRJ. Departamento de Geologia e Paleontologia. Setor de Paleobotânica e Paleopalinologia.

scheelybert@mn.ufrj.br

(**) University of Arizona. Department of Anthropology. Tucson, Arizona.dklokler@email.arizona.edu $(* * *)$ Museu Nacional, Universidade Federal do Rio de Janeiro-UFRJ. Departamento de Antropologia. mgaspar@alternex.com.br (****) Museu de Arqueologia e Etnologia, da Universidade de São Paulo.lfiguti@usp.br em análise. Da mesma forma opera a arqueologia. No entanto, estando a atenção dos estudiosos muito mais voltada para as alterações decorrentes dos processos naturais associados ao desenrolar do tempo (perda e ganho de materiais), são raras as reflexões sobre amostragem do universo conforme ele se apresenta no momento de estudo e as reflexões sobre a representatividade da área escavada. Para muitos pesquisadores, os contornos dos sítios arqueológicos representam limites relacionados apenas com a área a ser escavada, sem uma reflexão mais detida sobre a articulação entre unidades sociológicas, que só fazem sentido integrando um conjunto maior. No estudo da ocupação pré-colonial do Brasil, pouca atenção tem sido dada para a identificação de unidades 
SCHEEL-YBERT, R.; KLÖKLER, D.; GASPAR, M.D.; FIGUTI, L. Proposta de amostragem padronizada para macro-vestígios bioarqueológicos: antracologia, arqueobotânica, zooarqueologia. Rev. do Museu de Arqueologia e Etnologia, São Paulo, 15-16: 139-163, 2005-2006.

que tenham significado sociológico e a identificação da função de sítios arqueológicos.

A integração, ao trabalho arqueológico, das chamadas “disciplinas associadas” é um fenômeno cada vez mais freqüente e que tem trazido uma série de informações importantes ao conhecimento do processo de ocupação do que é hoje o território brasileiro. À medida que os arqueólogos se distanciam da arqueologia meramente descritiva, do simples inventário, a escavação passa a fornecer informações não somente sobre artefatos, dieta alimentar, habitação, economia doméstica, mas também sobre sistemas socioculturais, ambiente, entre outros. Os trabalhos naturalistas e os estudos paleoambientais não são mais apenas um adendo ao conhecimento do sítio, mas auxiliam na construção de interpretações e fazem parte integrante do campo atual da arqueologia (Scheel et al. 1996).

Neste sentido, é muito importante que tais estudos sejam levados em consideração desde o planejamento da escavação arqueológica (ScheelYbert et al., no prelo). Idealmente, os especialistas devem ser contactados antes de sua realização, durante a fase de definição do projeto de pesquisa, a fim de que, participando do trabalho de campo, eles possam contribuir para a definição de estratégias metodológicas que conduzam a uma otimização da recuperação de macro e micro-vestígios de origem vegetal e animal. No entanto, estes especialistas ainda são raros no Brasil e não podem atender à demanda de toda a comunidade arqueológica. Por isso, este artigo tem como objetivo estabelecer um protocolo de amostragem que possa atender às necessidades da pesquisa arqueológica no campo e conduzir a uma coleta sistematizada de restos botânicos e faunísticos.

A padronização das coletas de restos vegetais, para estudos em arqueobotânica e em antracologia, e de restos animais, para estudos em zooarqueologia, visa essencialmente tornar disponíveis amostras que conduzam à obtenção de dados comparáveis, em sítios diferentes, no que se refere ao paleoambiente, à dieta alimentar, e a informações paleoetnológicas de um modo geral.

Arqueobotânica é o estudo dos restos vegetais encontrados em contexto arqueológico (Ford 1979). Além de representar um termo geral que engloba o estudo de diferentes partes das plantas, com diversos objetivos, a arqueobotânica se refere especificamente aos métodos de coleta, análise e interpretação de dados que não envolvem a ação humana (Popper \& Hastorf 1988). Neste sentido, ela se diferencia da paleoetnobotânica, que se define como "a análise e interpretação de vestígios arqueobotânicos visando fornecer informações sobre as interações entre populações humanas e plantas” (Popper \& Hastorf 1988).

Muitos são os objetivos do estudo arqueobotânico. Por exemplo, ecólogos podem buscar nos restos vegetais evidências para a reconstrução de ambientes passados; botânicos podem estudar as mudanças morfológicas de certas plantas ao longo do processo de domesticação; arqueólogos se interessam pela forma como populações antigas utilizaram o ambiente para prover às suas necessidades básicas, em como as estratégias econômicas variaram ao longo do tempo, ou em como os restos vegetais encontrados em contexto funerário poderiam indicar uma oferenda de significado simbólico, assinalando diferenças de status social.

Muitas também são as disciplinas implicadas na análise arqueobotânica. Distinguem-se, particularmente, os estudos de macro-restos vegetais, como a antracologia (estudo dos restos de madeira carbonizada), a carpologia (estudo dos frutos e sementes), o estudo de tubérculos e raízes comestíveis, de fibras, de folhas, de madeiras não carbonizadas, entre outros, dos estudos de micro-restos vegetais, especialmente fitólitos, grãos de pólen e grãos de amido.

Os métodos de coleta apresentados neste artigo se limitam aos primeiros. Embora a maior parte das técnicas apresentadas tenham sido desenvolvidas para a coleta de amostras carbonizadas, elas normalmente se aplicam também à coleta de vestígios não-carbonizados.

Cabe ressaltar, no entanto, que, em condições normais de preservação, a conservação de restos vegetais não-carbonizados em sítios de regiões tropicais é incidental. Esta dificuldade de conservação faz com que a recuperação de restos alimentares carbonizados (frutos, sementes, tubérculos, raízes etc.) se revista da mais alta importância, podendo conduzir à obtenção de vestígios materiais concretos de atividades que muitas vezes continuam sendo inferidas simplesmente a partir de provas indiretas, como é o caso do consumo de vegetais e do cultivo.

Desde seu aparecimento, na França, na década de 70, a antracologia tem contribuído com uma série de importantes inovações para a compreensão do registro arqueológico. A primeira, que foi 
SCHEEL-YBERT, R.; KLÖKLER, D.; GASPAR, M.D.; FIGUTI, L. Proposta de amostragem padronizada para macro-vestígios bioarqueológicos: antracologia, arqueobotânica, zooarqueologia. Rev. do Museu de Arqueologia e Etnologia, São Paulo, 15-16: 139-163, 2005-2006.

seu objetivo inicial e sua contribuição mais evidente, se refere à reconstituição do meio ambiente no qual viviam as populações pré-históricas. A análise dos fragmentos de carvão conservados no sedimento retrata a vegetação em torno do sítio durante $o$ período de ocupação e, por dedução, do clima. A partir da conjugação de critérios paleoecológicos e arqueológicos, é possível determinar a ocorrência de mudanças climáticas, assim como de modificações do meio-ambiente provocadas pela atividade antrópica.

Por exemplo, estudos de antracologia e palinologia de oito sítios da região do Alto Ribatejo, em Portugal, mostraram que as comunidades neolíticas exploravam diversos biomas e evidenciaram um aumento da importância de formações vegetais abertas ao longo do tempo, em detrimento de florestas de galeria e de florestas de carvalho, o que foi atribuído a uma exploração muito intensiva da paisagem (Allué 2000).

Da mesma forma, estudos antracológicos realizados em vários sítios às margens do Eufrates, na Turquia e na Síria, indicaram que a paisagem do Oriente Próximo, atualmente árida e inteiramente desmatada, foi muito diferente durante a Idade do Bronze, apresentando florestas de carvalhos e florestas de estepe numa grande extensão, e a mais baixas altitudes do que estas ocorrem atualmente (Willcox 2002). Embora uma influência climática sobre esta mudança de vegetação não possa ser descartada, o autor atribui este processo principalmente a uma desertificação antrópica. O excesso de pastagens teria conduzido à destruição da vegetação e ao aumento da erosão, o que em conseqüência acarretou maior atividade eólica. Estas últimas, associadas à atividade constante e continuada dos animais, continuariam impedindo, até os dias de hoje, a regeneração da cobertura vegetal (Willcox 2002).

Interpretados de um ponto de vista paleoetnológico, os fragmentos de carvão dispersos no sedimento podem, além da reconstituição paleoambiental, fornecer informações importantes sobre a economia do combustível.

Na França, o estudo antracológico de sítios paleolíticos conduziu a uma reflexão aprofundada sobre a gestão dos combustíveis a as motivações dos grupos que utilizaram madeira, linhita, excrementos ou ossos de animais em suas fogueiras (ThéryParisot 2001). Argumentando que as práticas de coleta de lenha são muito diversas, dependendo do sítio e das condições encontradas pelos diferentes grupos humanos, e com base em experimentações, a autora demonstrou que não existe "seleção de espécies”, pois as propriedades combustíveis da madeira são condicionadas por fatores diversos, independentes da espécie, e que um grande número de variáveis pode influenciar na decisão de coletar determinada planta para lenha (acesso, distância do sítio, facilidade de coleta, tamanho, calibre, taxa de umidade, entre outros). Através de experimentações em laboratório, ela estabeleceu que, ao contrário do que se acreditava anteriormente, os ossos de animais ou a linhita não podem substituir inteiramente o uso de madeira para lenha, de um lado porque eles dependem do uso de madeira seca para iniciar a combustão, de outro por serem pouco apropriados para certas funções da fogueira, por exemplo a produção de brasas para cozimento indireto (osso), a iluminação e a defumação (linhita). O uso destes materiais no sul da França durante o Paleolítico, dentro de um ambiente florestado, se deveu a um processo de gestão dos combustíveis segundo suas propriedades e o interesse de seu uso. O uso de ambos representa uma dupla vantagem funcional e econômica. No caso de ossos de animais, a de melhorar a produção de chamas e de calor da fogueira, além de representar uma solução vantajosa para os problemas de aquisição e estocagem da madeira e de destruição das carcaças de animais consumidos. No caso da linhita, a de aumentar a duração da combustão e de diminuir a necessidade de atenção em relação ao fogo, permitindo que se reduza o estoque de madeira seca e que se conserve o fogo durante um longo tempo sem necessidade de reacendê-lo com freqüência. Note-se que esta autora demonstrou a completa impossibilidade de se fazer uma fogueira usando somente ossos, ou somente linhita. As "fogueiras de ossos" encontradas em alguns sítios paleolíticos não se devem a um uso exclusivo do osso como combustível, mas sim ao fato de que este material, quando queimado junto com a madeira, provoca uma carbonização completa desta última, deixando somente cinzas e restos de ossos carbonizados ao final da combustão (Théry-Parisot 2001).

No Brasil, foi demonstrado que a coleta aleatória de madeira morta constituía a principal fonte de lenha para populações sambaquieiras (Scheel-Ybert 2000, 2001a, 2001b). Este mesmo trabalho revelou que a madeira de Condalia sp, um arbusto da família Rhamnaceae, parece ter sido 
SCHEEL-YBERT, R.; KLÖKLER, D.; GASPAR, M.D.; FIGUTI, L. Proposta de amostragem padronizada para macro-vestígios bioarqueológicos: antracologia, arqueobotânica, zooarqueologia. Rev. do Museu de Arqueologia e Etnologia, São Paulo, 15-16: 139-163, 2005-2006.

selecionada por razões econômicas ou cerimoniais (Scheel-Ybert 2001a). No entanto, uma análise cuidadosa dos dados permitiu demonstrar que, se a seleção de espécies concerne apenas a uma fração limitada do cortejo vegetal, ela não afeta a validade das interpretações paleoambientais (Scheel-Ybert 1999).

Além disso, há outras aplicações da antracologia, que vão desde a identificação de restos de madeira carbonizada associados a estruturas bem identificadas na escavação (estacas, estruturas de habitação, objetos queimados), o que pode indicar quais tipos de madeira eram utilizados para aplicações específicas (Bernard \& Thibaudeau 2002; Durand 2002), até a identificação de restos alimentares carbonizados, que se conservam junto com o material antracológico propriamente dito, e podem fornecer importantes indicações sobre dieta, consumo de vegetais, manejo ou cultivo.

No Brasil, o estudo de um grande número de fragmentos de carvão de sambaquis conduziu à recuperação de vários fragmentos de tubérculos, em particular restos de carás (Dioscorea sp) (Scheel-Ybert 2001a). A preservação de tubérculos no registro arqueológico sendo particularmente difícil, sua conservação sugere que este alimento, muito rico em amido, contribuía substancialmente para a alimentação dos sambaquieiros, e que os vegetais eram mais importantes em sua alimentação do que se considera usualmente. Este fato, corroborado por outros indícios de caráter etnobotânico, conduziu à hipótese da existência de manejo na sociedade sambaquieira (Scheel-Ybert 2003). A associação destes resultados àqueles obtidos através de análises de patologia dental em sambaquieiros (Wesolowski 2000), que indicaram que, pelo menos em alguns sítios, as freqüências de cáries são análogas às de horticultores, e mesmo agricultores, permitiu levantar a questão de saberse se algum tipo de produção de alimentos já existia naquela época (Scheel-Ybert et al. 2003).

Note-se que, neste caso, o estudo antracológico conduziu a uma mudança na percepção da dieta alimentar dos sambaquieiros, passando de uma dependência exclusiva de recursos marinhos (moluscos e peixes) para algo mais complexo. A inclusão de vegetais na dieta pode explicar a ocorrência de cáries, e permitir um melhor entendimento da área de captação de recursos dos sambaquieiros.

Os poucos exemplos apresentados ressaltam a contribuição significativa da antracologia ao conhecimento da pré-história, pois os carvões constituem uma fonte inestimável de informações de diversas ordens. No entanto, ainda é raro que os arqueólogos brasileiros coletem estes vestígios de modo sistemático, pois restos carbonizados costumam ser recuperados exclusivamente visando datações radiocronológicas.

Da mesma forma, a zooarqueologia, apesar de conhecida por arqueólogos brasileiros desde seus primórdios como disciplina, em meados do século XIX, ainda é vista essencialmente como um meio de identificar e contabilizar as espécies animais encontradas em determinado sítio. Estudos zooarqueológicos no Brasil têm seu potencial subaproveitado, principalmente pelo desconhecimento da maioria dos pesquisadores da ampla e diversificada contribuição que a pesquisa dos restos faunísticos pode fornecer à arqueologia. Estudos faunísticos podem, e devem, extrapolar as meras listas de espécies presentes nas amostras, geralmente apresentadas em anexo ao final de relatórios de pesquisa. Para isso, o zooarqueólogo deve estar envolvido no projeto de escavação, de maneira que possa desenvolver o melhor método de coleta, a partir dos objetivos e hipóteses de pesquisa (Klökler 2001). A estratégia de campo deve ser adaptada às características do sítio e aos objetivos e prioridades dos pesquisadores.

Por exemplo, a coleta sistemática apenas de ossos de mamíferos, ou a seleção de alguns elementos maiores e melhor preservados, tende a falsear as informações sobre a importância dos restos animais no sítio e a representatividade de cada espécie no contexto geral. Da mesma forma, a coleta exclusivamente de restos de fogueiras, ou a seleção, para a antracologia, dos poucos fragmentos de carvão maiores e mais visíveis durante a escavação, impede a realização de um estudo paleoecológico visando à reconstituição paleoambiental da área.

Figuti (1989, 1992, 1993) foi o primeiro autor a ressaltar a necessidade de maior cuidado na elaboração de metodologias de campo para amostras zooarqueológicas no Brasil. Sua influência tem sido sentida nos trabalhos mais recentes em zooarqueologia, porém estes esforços ainda são isolados na disciplina (Klökler 2001; Nishida 2001).

A adoção de um protocolo minucioso para guiar a coleta de amostras de vestígios faunísticos contribuirá para a padronização dos estudos 
SCHEEL-YBERT, R.; KLÖKLER, D.; GASPAR, M.D.; FIGUTI, L. Proposta de amostragem padronizada para macro-vestígios bioarqueológicos: antracologia, arqueobotânica, zooarqueologia. Rev. do Museu de Arqueologia e Etnologia, São Paulo, 15-16: 139-163, 2005-2006.

zooarqueológicos, permitindo a posterior comparação entre sítios de diversas regiões do país. A falta de padronização em estudos zooarqueológicos dificulta as interpretações sobre o uso e importância de vestígios animais no passado, impedindo que determinados temas sejam estudados em profundidade e que um conhecimento bem embasado sobre o assunto seja construído. Dessa forma, uma questão que poderia ser bem equacionada torna-se uma preocupação constante entre os zooarqueólogos brasileiros (Figuti 1992; Figuti \& Klökler 1996; Klökler 2001).

Grande parte dos trabalhos em zooarqueologia no Brasil é feita a partir de vestígios advindos de coletas seletivas. Entende-se por "coleta seletiva” a recuperação manual de ossos grandes e/ou fragmentos que aparentam ter elementos para identificação (Wheeler \& Jones 1989). No entanto, raramente os pesquisadores esclarecem os critérios de seleção de certos elementos em detrimento de outros. Diferenças em termos de experiência em campo ou conhecimentos em biologia contribuem para uma descontinuidade em relação aos elementos coletados (ossos, dentes, conchas etc). $\mathrm{Na}$ grande maioria dos casos, ossos de mamíferos são mais facilmente reconhecidos, o que gera inferências errôneas sobre a importância da caça entre grupos pré-históricos. Nos trabalhos feitos em Cosipa (Figuti 1989, 1992) e no sítio Enseada-I (Bandeira 1992), os pesquisadores somente tiveram acesso a amostras coletadas seletivamente, e em consequiência, apesar de seus esforços, o trabalho interpretativo foi parcialmente comprometido, especialmente as análises relacionadas à dieta, subsistência, e estratégias de pesca.

Além de diminuir o potencial informativo do material arqueológico, coletas seletivas também dificultam a padronização do volume da amostras. O controle do tamanho das amostras coletadas para a pesquisa (por peso ou volume) é fundamental, pois ele influencia diretamente a quantidade de espécies animais recuperadas em um sítio (Grayson 1984). Quando os resultados de amostras de diferentes tamanhos são comparados, as diferenças em diversidade identificadas não serão necessariamente relevantes para o estudo das sociedades préhistóricas, mas sim consequiência da metodologia adotada em campo.

A falta de padronização de amostras por volume impede a verificação de diferenças densimétricas e volumétricas e mascara as propor- ções de elementos composicionais das camadas dos sítios estudados. As amostras reservadas para zooarqueologia no sítio Espinheiros-II (Figuti \& Klökler 1996) não possuíam volume padronizado, o que impediu que os autores avaliassem mudanças na técnica de pesca e que fosse estabelecida com precisão a época da mesma.

A amostragem zooarqueológica em sambaquis é onerosa em tempo e pessoal envolvido. Portanto, suas metas devem ser claras, e seus métodos os mais rentáveis em termos de tempo/resultados. Um primeiro aspecto da pesquisa zooarqueológica em sambaquis é o próprio estudo de suas camadas, que nos remete obrigatoriamente à análise de sua composição faunística. Porém, além dos índices tradicionais em zooarqueologia, NISP e MNI (ou "Número de Peças Identificadas" e "Número Mínimo de Indivíduos”), o estudo das camadas requer também índices que forneçam dados sobre a fragmentação e a compactação dos vestígios, os quais conduzem a informações sobre aspectos da formação do sítio.

O grau de fragmentação de vestígios animais fornece evidências sobre processo de formação do sítio (Klökler 2001), localização de áreas de atividade (Rouse, 2004) e função do sítio (Piana et al. 1998), além de prover dados acerca do processamento, consumo e descarte de produtos animais.

Estudos de granulometria no sítio Jabuticabeira-II (Santa Catarina) revelaram-se muito interessantes. Os índices de fragmentação dos restos de bivalves, que foram a princípio calculados visando o reconhecimento de áreas de circulação intra-sítio, se tornaram elementos básicos para a interpretação do processo de formação do sítio. Verificou-se que certas camadas contêm conchas com maior grau de integridade, e que em muitos casos as valvas ainda estavam unidas. Essas camadas, que formam montículos recobrindo áreas funerárias, são caracterizadas pela predominância de berbigões, por um sedimento arenoso solto e pela integridade de seus componentes - mesmo mariscos, moluscos cujas valvas são finas e frágeis, encontram-se inteiros e fechados. Tais condições de preservação contradizem interpretações que consideravam o sítio como espaço habitacional. Por outro lado, as camadas funerárias deste mesmo sítio contêm maiores porcentagens de conchas quebradas e um sedimento mais compacto, indicando que foram submetidas a pisoteamento (Klökler 2001). 
SCHEEL-YBERT, R.; KLÖKLER, D.; GASPAR, M.D.; FIGUTI, L. Proposta de amostragem padronizada para macro-vestígios bioarqueológicos: antracologia, arqueobotânica, zooarqueologia. Rev. do Museu de Arqueologia e Etnologia, São Paulo, 15-16: 139-163, 2005-2006.

Uma questão fundamental em arqueologia diz respeito à dieta, e para isso geralmente recorre-se a estudos de zooarqueologia. Na literatura brasileira, há diversos exemplos de trabalhos que pretendem investigar a dieta de populações pré-históricas (Garcia 1970; Schoor 1975; Bandeira 1992; Bonetti 1997; entre outros). No entanto, sem uma amostragem padronizada de todos os níveis de ocupação em diferentes áreas do sítio, coleta de todos os elementos faunísticos, e uso de peneiras com malha de $2 \mathrm{~mm}$, qualquer análise de possíveis mudanças de dieta terá resultados inconclusivos.

Note-se que a mesma observação é válida no que se refere a investigações em arqueobotânica e antracologia. Estas disciplinas são muito mais recentes no Brasil, e poucos estudos abordando consumo de produtos vegetais já foram publicados (e.g. Dias \& Carvalho 1983; Tenório 1991; Resende \& Cardoso 1995-96; Scheel-Ybert 1999, 2001a). No entanto, a raridade destes restos torna ainda mais importante a amostragem padronizada, coleta extensiva, flotação, uso de peneiras apropriadas e análise de um grande número de fragmentos, sem o que não se pode sequer avaliar a importância deste consumo para a dieta de populações préhistóricas.

A análise zooarqueológica, porém, não se restringe às investigações sobre a alimentação de povos pré-históricos, e pode ser utilizada com vantagem para a compreensão de processos de formação de sítios (Klökler 2001). A análise da composição faunística das diferentes estruturas e camadas do sambaqui Jabuticabeira-II contribuiu para a redefinição de algumas noções sobre seu processo de formação, pondo em foco a importância do ritual funerário no incremento do sítio.

Estruturas cônicas no perfil (Fig. 1) chamaram a atenção da equipe e foram primeiramente consideradas evidências de superfícies de habitação, representando a localização de cabanas. A coleta de amostras provenientes dessas marcas de estacas demonstrou que $90 \%$ do sedimento que as preenche é composto por restos de peixes, além de seixos inteiros ou fragmentados. $\mathrm{O}$ aumento excepcional do número de peixes no sedimento contido nas marcas de estacas é inconsistente com uma interpretação desses vestígios como restos de alimentação cotidiana. Ao contrário, a presença de sepultamentos em diferentes áreas do sambaqui, aliada à composição dos sedimentos recuperados no interior das marcas de estacas e das lentes enegrecidas, forneceu subsídios para a caracterização do sambaqui Jabuticabeira-II como sítio funerário (Fish et al. 1998; Klökler 2001, 2003a, 2003b). A localização das estruturas em V, sempre em estrita associação com fogueiras e sepultamentos, muitas vezes circundando os mesmos, parece indicar que as marcas de estacas são vestígios de estruturas funerárias construídas para proteção do espaço ritual.

Os ossos de peixes encontrados nas lentes escuras e nas fogueiras, sempre associadas a contextos funerários, são de maior porte e mais abundantes que os recuperados nas camadas de conchas, o que sugere a realização de banquetes em homenagem aos mortos. De fato, esta grande quantidade de restos de peixes não pode ser explicada como o resultado de refeições comuns, mas somente por eventos de grande magnitude. Estudos preliminares indicam a presença de aproximadamente 300 peixes associados a apenas uma fogueira e uma média de 88 peixes em cada cova, acompanhando os corpos (Klökler 2003b).

A análise zooarqueológica também permitiu aos pesquisadores identificar a existência de técnicas distintas de captação de recursos aquáticos: a pesca rotineira de espécimes de pequeno porte, que demanda o uso de algum tipo de rede de arrasto, e a pesca de grandes peixes vinculada especificamente ao festim fúnebre (Klökler 2003a, 2003b; Gaspar \& Klökler 2004). Essa diferenciação confirma a importância dos banquetes fúnebres que demandariam a utilização de técnicas específicas de pesca para obter os recursos necessários para eventos em memória aos ancestrais.

Outra importante contribuição da zooarqueologia para o entendimento de processos de formação em sítios conchíferos pode ser encontrada no estudo do sambaqui Espinheiros-II. Neste sítio, a análise zooarqueológica dos sedimentos de duas áreas diferentes (uma sondagem e um perfil) permitiu identificar duas fases distintas em sua formação (Figuti \& Klökler 1996). Em sua primeira fase, o sítio é constituído quase exclusivamente por conchas de berbigão, resultado de coletas maciças de moluscos nos bancos lodosos localizados próximos ao sambaqui, provavelmente com o intuito de formar uma plataforma elevada, ou um aterro de conchas. Na segunda fase de sua formação e ocupação, a coleta de berbigões é acompanhada pela coleta de mariscos e ostras, além de uma atividade pesqueira intensa, o que 
SCHEEL-YBERT, R.; KLÖKLER, D.; GASPAR, M.D.; FIGUTI, L. Proposta de amostragem padronizada para macro-vestígios bioarqueológicos: antracologia, arqueobotânica, zooarqueologia. Rev. do Museu de Arqueologia e Etnologia, São Paulo, 15-16: 139-163, 2005-2006.

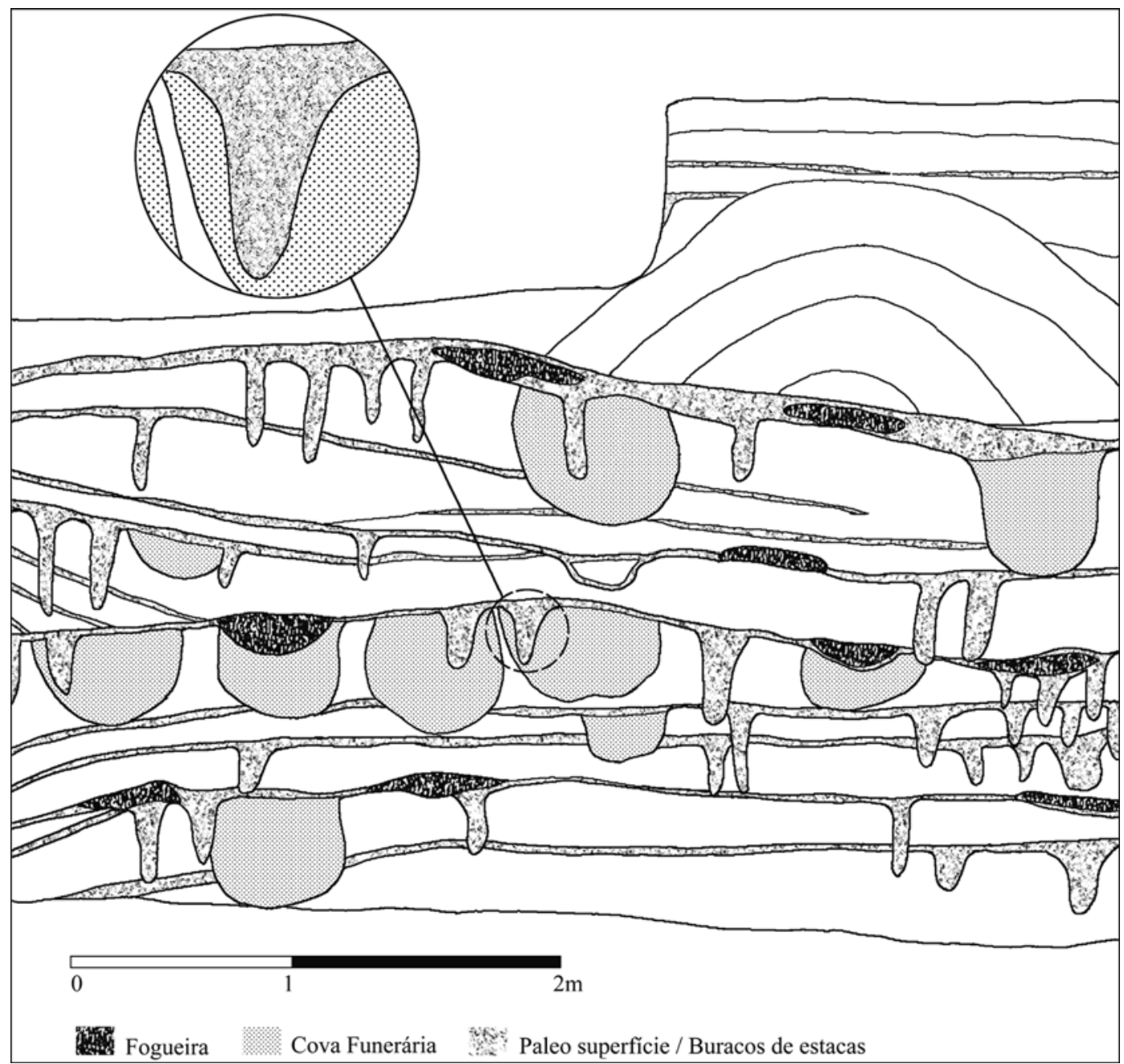

Fig. 1 - Seção de um perfil mostrando a estrutura estratigráfica do Sítio Jabuticabeira-II, estado de Santa Catarina, Brasil (adaptado de Fish et al. 2000). Estruturas em forma de V no perfil representam buracos de estaca (ver detalhe).

indica o desenvolvimento de um padrão mais complexo de captação de recursos. Esta diversidade de elementos faunísticos nos níveis superiores está provavelmente associada à ocupação do sítio e à sua utilização como local de habitação.

Estudos de zooarqueologia baseados na análise de sazonalidade, na Flórida (Russo \& Quitmyer 1996), contribuíram para derrubar a concepção de que os povos do Arcaico eram nômades e exploravam a costa apenas no inverno, comprovando que a coleta de vieiras (Argopecten irradians) ocorria principalmente no verão, e que esses grupos ocuparam áreas costeiras o ano inteiro.

A zooarqueologia tem contribuído, também, para estabelecer a função de áreas ou compartimentos no interior de sítios arqueológicos. A análise de vestígios faunísticos não modificados (não transformados em artefatos), foi utilizada para acessar a função de quartos e casas no Arizona, nos EUA. Neste caso, distinções entre quantidade e distribuição de produtos comestíveis e não comestíveis, presença de ossos não modificados, e grau de fragmentação e características da fauna encontrada em diferentes contextos, permitiram 
SCHEEL-YBERT, R.; KLÖKLER, D.; GASPAR, M.D.; FIGUTI, L. Proposta de amostragem padronizada para macro-vestígios bioarqueológicos: antracologia, arqueobotânica, zooarqueologia. Rev. do Museu de Arqueologia e Etnologia, São Paulo, 15-16: 139-163, 2005-2006.

diferenciar cômodos com função habitacional, cerimonial e de armazenagem (Clark 1998).

A análise dos contextos de sepultamentos de animais no sudoeste americano (Hill 2000) indicou que existem diferentes padrões de enterramento, correspondentes a lixo cerimonial, oferendas dedicatórias e sepultamentos simples. O estudo é relevante por ressaltar a complexidade das interações entre populações pré-históricas e animais. As pesquisas descritas comprovam a importância da zooarqueologia para o estudo de vários domínios do comportamento humano.

\section{Metodologia}

A representatividade de uma amostra é condição essencial para a validade dos resultados obtidos e sua posterior interpretação, por isso a escolha do método a ser empregado para a coleta de material merece cuidadoso estudo. Para que o trabalho faça sentido, é preciso que as amostras sejam representativas dos sítios de origem (Cherry 1978; Popper 1988; Wheeler \& Jones 1989).

Como nem sempre é possível obter uma amostra ideal, seja por motivos relacionados a tempo, verba, e/ou desenho do projeto, é procedente estabelecer procedimentos mínimos que viabilizem não só a construção de interpretações bem embasadas como, também, futuras comparações entre sítios e regiões.

Apesar de em alguns casos o volume de material coletado ser aparentemente pequeno em relação ao tamanho do sítio estudado, é sabido que a coleta de quantidades enormes de material pode fornecer dados redundantes, além de resultar em altos custos de transporte, análise e armazenamento (Waselkov 1987; Reitz \& Wing 1999). O coletor precisa ter em mente que estratégias de amostragem são uma forma de adequação entre a necessidade de coletar o máximo possível e a realidade de que as amostras deverão ser processadas, identificadas e interpretadas em tempo para publicação (O’Connor 2000). A coleta da totalidade dos vestígios faunísticos e botânicos representa uma situação ideal, entretanto, em alguns sítios e em algumas situações isto é impossível. Por isso, o pesquisador deve definir o número mínimo de amostras e o tamanho das mesmas em relação à especificidade de cada sítio e pesquisa.

A antracologia é uma disciplina relativamente nova no Brasil, onde a preocupação com o estabelecimento de uma metodologia de coleta de campo adaptada às condições tropicais se fez sentir desde os primeiros trabalhos (Scheel-Ybert 1998, 1999, 2000). Por esta razão, já existem várias publicações fornecendo informações sobre a metodologia antracológica e aspectos teóricos relacionados a esta disciplina (Scheel et al. 1996; Ybert et al. 1997; Scheel-Ybert 2004a, 2004b; 2005).

Um estudo antracológico qualitativa e quantitativamente confiável só é possível a partir da análise de um número razoável de carvões para cada estrato. A superfície do sítio arqueológico deve ser amostrada o mais amplamente possível, para cada nível estratigráfico, a fim de que se obtenha a maior representatividade possível em termos de diversidade taxonômica, e que se possa avaliar a distribuição espacial dos carvões, o que pode conduzir a interpretações relacionadas a diferentes áreas de atividade.

A comparação de curvas de saturação e de curvas de Gini-Lorenz (Scheel-Ybert 2002) indicou que 200 a 300 fragmentos de carvão por amostra, no mínimo, são necessários para uma boa interpretação paleoambiental. É fundamental distinguir, no campo, as amostras provenientes de carvões concentrados das amostras de carvões dispersos, pois uma reconstituição paleoecológica confiável deve ser baseada essencialmente nos carvões dispersos.

Embora a idéia de carvão reporte imediatamente àquela de fogueira, e efetivamente os carvões concentrados sejam os mais visíveis na escavação, as camadas arqueológicas apresentam sempre carvões dispersos, que podem revelar-se abundantes por peneiragem do sedimento, os quais provêm da limpeza sucessiva de fogões ou fogueiras ou do espalhamento dos restos de combustão por processos pós-deposicionais (vento, atividade humana, atividades da fauna etc.). Os carvões concentrados, por sua vez, em geral se originam de fogos ou fogueiras que tenham tido uma curta utilização no tempo, representando uma amostra pouco significativa da vegetação como um todo; eles podem também estar relacionados a uma construção, um objeto ou uma atividade especializada, reconhecíveis no terreno a partir de critérios arqueológicos, e cujo estudo oferece informações paleoetnológicas (Scheel et al. 1996).

Da mesma forma, estudos da fauna dependem de coletas em diferentes áreas de atividade, as 
quais são essenciais para que o arqueólogo tenha acesso aos diversos usos de animais pelas populações pré-históricas. Vestígios faunísticos não se restringem a regiões onde supostamente o grupo se reuniu para comer (em torno de fogueiras), porém localizam-se também na periferia do sítio, em acumulações resultantes da limpeza das áreas comunitárias, nos locais onde se manufaturam instrumentos ósseos ou conchíferos, em contextos rituais etc. Devido a essa diversidade espacial, projetos de pesquisa devem incluir em sua metodologia amostragens distintas dependendo do sítio e das hipóteses do projeto.

A fim de maximizar a recuperação de informações antracológicas, arqueobotânicas e zooarqueológicas, e diminuir o investimento em trabalhos de campo, foram desenvolvidos protocolos de amostragem que podem ser utilizados em conjunto para as três disciplinas.

\section{Amostragem}

Protocolos de amostragem abrangendo diversos cenários de coleta para antracologia, arqueobotânica e zooarqueologia são propostos a seguir. Sugere-se que eles sejam fotocopiados, plastificados e utilizados, no campo, durante a escavação. Um modelo de formulário de coleta para antracologia e zooarqueologia é igualmente proposto (Fig. 2). Cópias eletrônicas do mesmo podem ser obtidas dos autores sob demanda.

Embora o formulário seja o mesmo para todas as disciplinas, é importante preencher folhas separadas para cada tipo de material (restos vegetais carbonizados / restos vegetais não carbonizados / fauna), já que sua análise geralmente é feita por especialistas diferentes.

\subsection{Amostragem de estruturas}

As amostras de estruturas (tais como fogueiras e depósitos associados, objetos queimados, concentrações de ossos, buracos de estaca, silos, restos vegetais não carbonizados etc.) devem ser coletadas separadamente e bem identificadas. Seguir o protocolo de coleta (Fig. 3) e o protocolo de conservação de material biológico (Fig. 4).

Não é necessária a padronização do tamanho da amostra. Sempre identificar o tipo de estrutura, número, tamanho e preencher um formulário onde deve ser relacionada cada amostra, com descrição minuciosa do sedimento e, sempre que possível, um croquis representativo (vide "Formulário de coleta" na Fig. 2).

\subsection{Amostragem exaustiva}

Aplica-se a sítios onde há pouca quantidade de carvões ou de vestígios faunísticos, a casos nos quais a intervenção no sítio for muito pequena ou quando for decidida uma peneiragem de todo o sedimento arqueológico durante a escavação. Seguir protocolo de coleta (Fig. 5).

\subsection{Amostragem sistemática (durante a decapagem)}

Devido à necessidade de se levar em consideração a variabilidade estratigráfica e a heterogeneidade de depósitos inerentes aos sítios, é indispensável que se façam amostragens concomitantes à escavação arqueológica. A coleta sistemática consiste em amostrar o material das diversas quadras escavadas. Para isso, seguir protocolo de coleta (Fig. 6).

A situação ideal é que seja coletada uma amostra em cada unidade de escavação (por exemplo, em cada quadrícula), em cada decapagem, mas este procedimento pode ser adaptado de acordo com a escavação (Fig. 7). A superfície da unidade a ser amostrada deve perfazer entre $1 / 4$ e a totalidade de cada metro quadrado, em função da riqueza da camada em carvões (Chabal 1988, 1997) ou em restos faunísticos, e das contingências da escavação. O material deve ser coletado e peneirado de acordo com uma das técnicas especificadas posteriormente. Não deixar de identificar o tipo de coleta, sempre anexando etiquetas identificadoras. Um formulário de coleta relacionando todas as amostras, com informações detalhadas sobre cada uma delas, deve ser sistematicamente preenchido (Fig. 2).

No caso da amostragem zooarqueológica, os pesquisadores podem escolher entre utilizar como padronização coletar o sedimento, em cada quadrícula, com (1) baldes, (2) colunas de 25x25x10cm ou (3) “caixinhas”. Neste último caso, os pesquisadores podem definir as dimensões da amostra que querem retirar de cada quadrícula, 
Sítio:

Coletor:

Data:

\section{Material:}

$$
\begin{aligned}
& \square \text { carvão } \\
& \square \text { fauna } \\
& \square \text { outros }
\end{aligned}
$$

\section{$\square$ disperso no sedimento \\ $\square$ concentrado em estruturas (descrever e propor interpretação)}

Modo de coleta: $\square$ manual

$\square$ peneiragem a seco

$\square$ flotação
Malha peneira:

$\square$ outra: $\square 2 \mathrm{~mm}$

\begin{tabular}{|c|c|c|c|c|c|c|}
\hline $\mathrm{N}^{\circ}$ & localização & nível & $\begin{array}{c}\text { camada } \\
\text { arqueológica }\end{array}$ & $\mathrm{n}^{\circ}$ baldes* & sedimento & obs \\
\hline 71 & Quadra 5C & 35 & 4 & 3 & $\begin{array}{l}\text { Areno-argiloso, coloração } \\
\text { marrom-escura }\end{array}$ & \\
\hline 72 & Trincheira 2 & 50 & $5 b$ & 1 & Acinzentado & Fogueira \\
\hline 73 & Perfil sul & $30-40$ & 2 & 9 & $\begin{array}{l}\text { Matriz orgânica escura c/ } \\
\text { conchas dispersas }\end{array}$ & \\
\hline & & & & & & \\
\hline & & & & & & \\
\hline & & & & & & \\
\hline & & & & & & \\
\hline & & & & & & \\
\hline & & & & & & \\
\hline & & & & & & \\
\hline & & & & & & \\
\hline & & & & & & \\
\hline & & & & & & \\
\hline & & & & & & \\
\hline & & & & & & \\
\hline & & & & & & \\
\hline
\end{tabular}

$\square 4 \mathrm{~mm}$

Observações / croquis: no verso

* Pesar o sedimento dos baldes antes de peneirar e anotar em folha anexa ou no verso desta.

Fig. 2 - Modelo de formulário de coleta para antracologia, arqueobotânica e zooarqueologia. Todas as amostras coletadas devem ser relacionadas em formulários similares, fornecendo sempre o maior número de informações possível sobre cada uma. Utilize folhas separadas para cada disciplina. Cópias eletrônicas deste formulário podem ser obtidas dos autores sob demanda. 


\section{Protocolo de amostragem (1)}

\section{Carvões concentrados e outros restos vegetais (fogueiras, frutos, estacas, etc.); vestígios faunísticos concentrados ou de características especiais}

1. Carvões concentrados, restos faunísticos e vegetais de interesse especial, facilmente evidenciados na escavação, podem ser coletados manualmente (coleta exaustiva), mas somente se houverem poucos fragmentos.

2. Quando o material encontrado fôr abundante, o sedimento deve ser peneirado. Pode ser feita peneiragem ou flotação (malha de 2 ou $4 \mathrm{~mm}$ ).

3. Todos os carvões, restos faunísticos e restos botânicos retidos pela peneira devem ser coletados.

4. Seguir o "Protocolo de conservação de material biológico".

Fig. 3 - Protocolo de amostragem (1). Roteiro para coleta de carvões concentrados e outros restos vegetais (fogueiras, frutos, estacas etc.) e de vestígios faunísticos concentrados ou de características especiais.

\section{Protocolo DE CONSERVAÇÃo DE MATERIAL BIOLÓGICO}

1. Colocar o material amostrado (seco) em sacos plásticos.

2. Preparar a etiqueta no momento da coleta, informando a localização exata da amostra (quadra, perfil, camada, posição da amostra, profundidade etc.), a forma de coleta (manual ou peneira, "decapagem", "perfil", malha da peneira), data, coletor etc. Sempre preencher as etiquetas e o formulário de coleta.

3. Colocar a etiqueta num saco plástico separado e colocar no interior do saco com a amostra ou grampear junto com este. Nunca colocar uma etiqueta de papel diretamente em contato com a amostra.

4. Sempre guardar o material biológico separado de outros vestígios arqueológicos. Nunca colocar peso sobre os carvões ou ossos (p.ex. nunca misturar carvões ou ossos com lítico), pois eles são frágeis e se fragmentam facilmente.

Fig. 4 - Protocolo de conservação de material biológico. Roteiro para acondicionamento de macro-restos vegetais e animais visando análises de antracologia, arqueobotânica $e$ zooarqueologia. 


\section{Protocolo de Amostragem (2)}

\section{Restos vegetais e faunísticos dispersos - amostragem exaustiva}

1. Nos casos de sítios onde há pouca quantidade de carvões ou de vestígios faunísticos, se a intervenção no sítio fôr muito pequena ou se fôr decidida uma peneiragem de todo o sedimento arqueológico durante a escavação, pode-se optar por recolher todos os carvões e material faunístico da peneira em triagem posterior.

2. Seguir o "Protocolo de conservação de material biológico".

Fig. 5 - Protocolo de amostragem (2). Roteiro para coleta de restos vegetais e faunísticos dispersos, a ser utilizado em casos de amostragem exaustiva (todos os vestígios encontrados).

\section{Protocolo de AMOSTragem (3)}

\section{Restos vegetais e faunísticos dispersos - coleta concomitante à escavação}

O sedimento arqueológico sempre apresenta carvões dispersos, e frequentemente também restos faunísticos, que passam desapercebidos a olho nu. Por isso, deve-se fazer uma amostragem sistemática concomitante à escavação, cuja malha deve ser definida em função da riqueza do sítio e das possibilidades do campo. Esta amostragem é importante para fornecer uma amostra representativa de todo o material existente no sítio.

Exs.: (1) Coletar o sedimento de $1 / 4$ de cada quadrícula, em cada decapagem; (2) coletar um balde de sedimento em cada decapagem, em cada quadrícula da escavação; (3) fazer uma coluna de $25 \times 25 \times 10 \mathrm{~cm}$ em cada quadrícula; (4) coletar uma "caixinha" em cada quadrícula.

1. Coletar o sedimento destinado à amostra antracológica e zooarqueológica em baldes, ou em "caixinhas". Se a estratégia definida fôr a de coletar "1 balde por decapagem", enchê-los sempre até a borda.

2. Peneirar o sedimento amostrado. Pode ser feita peneiragem ou flotação (malha de 2 ou $4 \mathrm{~mm}$ ).

3. Todos os carvões, restos faunísticos e restos botânicos retidos pela peneira devem ser coletados.

4. Seguir o "Protocolo de conservação de material biológico".

Fig. 6 - Protocolo de amostragem (3). Roteiro para coleta de restos vegetais e faunísticos dispersos, a ser utilizado em casos de amostragem sistemática concomitante à escavação. 
SCHEEL-YBERT, R.; KLÖKLER, D.; GASPAR, M.D.; FIGUTI, L. Proposta de amostragem padronizada para macro-vestígios bioarqueológicos: antracologia, arqueobotânica, zooarqueologia. Rev. do Museu de Arqueologia e Etnologia, São Paulo, 15-16: 139-163, 2005-2006.

construir uma caixa de madeira (Fig. 8) e utilizá-la ao invés de baldes. Os dois métodos mantêm os mesmos parâmetros de volume para todas as amostras, porém o uso da caixinha facilita a coleta.

Embora muito útil para a zooarqueologia, o método da caixinha, isoladamente, não é aconselhado para a coleta de carvões, pois em geral a quantidade de sedimento coletada é insuficiente para a amostra antracológica.

Note que este protocolo se refere a sítios com condições normais de preservação. Em sítios onde as condições de preservação são excepcionais a metodologia deve ser especialmente planejada, coletando-se todos os vestígios em sítios onde a preservação é particularmente baixa (especialmente, no caso dos restos faunísticos, em sedimentos ácidos) ou, ao contrário, diminuindo-se relativa- mente a amostragem quando a preservação é muito boa (por exemplo sítios-abrigo, onde a preservação de restos vegetais pode ser muito grande, ou sambaquis, onde há enorme quantidade de restos faunísticos).

Quando há necessidade de selecionar certas quadras para a amostragem, as áreas a serem amostradas devem ser definidas antes do início dos trabalhos, para que se evite a seleção de zonas com maior concentração de material, o que introduziria fatores de erro na posterior avaliação dos resultados obtidos. Esta seleção pode ser feita de modo aleatório (por exemplo, seleção de quadras através de números randômicos) ou sistemático (por exemplo, definição de coleta em quadras alternadas em cada linha do quadriculamento do sítio) (Fig. 7).

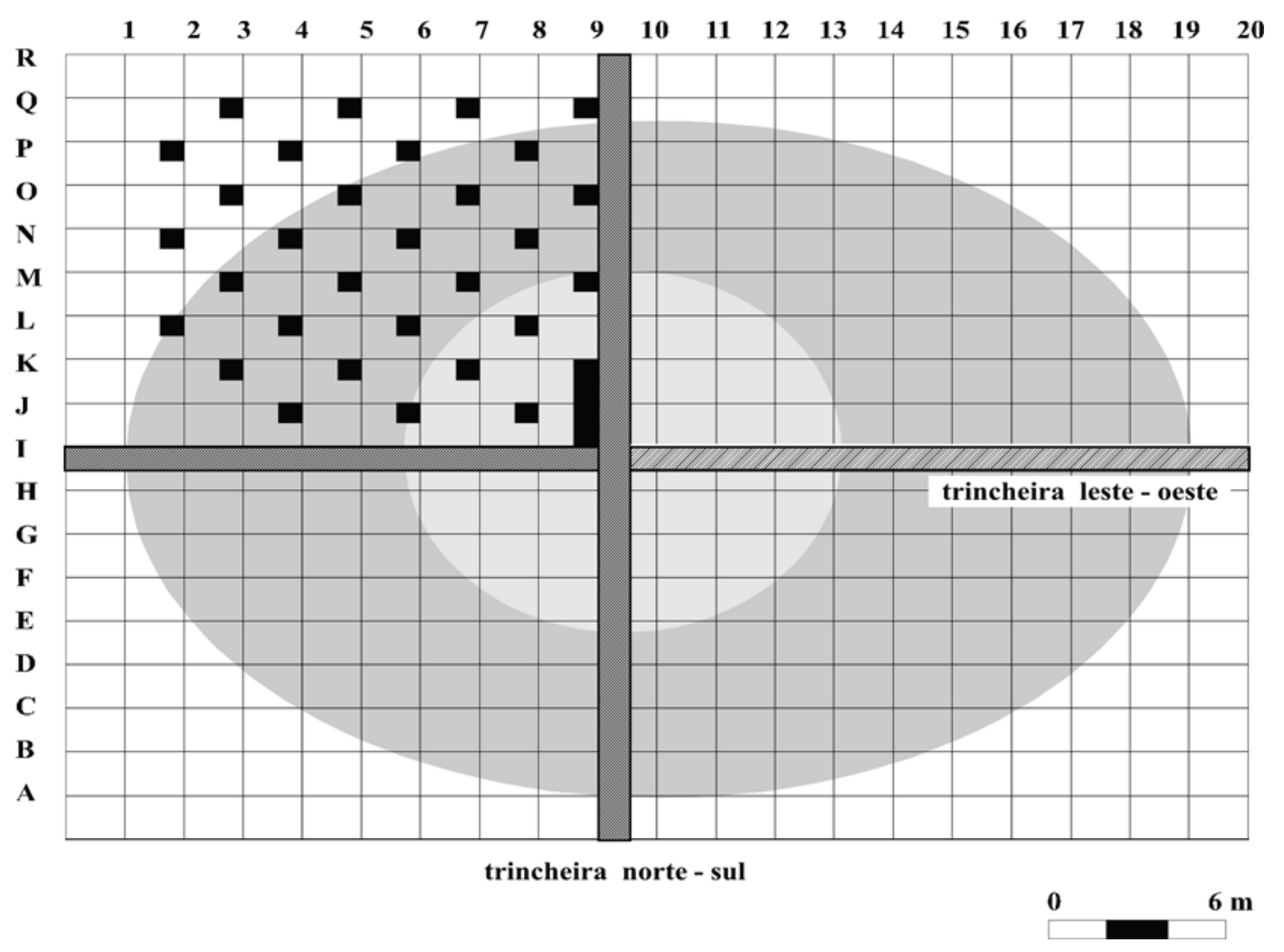

Fig. 7 - Exemplo de escavação do sítio Ilha da Boa Vista I (Tamoios, Cabo Frio,estado do Rio de Janeiro, Brasil), mostrando o quadriculamento do mesmo. A elipse cinza-escuro representa a área do sambaqui; o círculo claro, a área de maior concentração de vestígios (adaptado de Barbosa et al. 1994). A escavação arqueológica foi feita no quarto noroeste do sítio. Os quadrados pretos representam a amostragem antracológica durante a escavação (um balde de sedimento por decapagem, em quadrículas alternadas). O retângulo preto indica a localização do perfil antracológico (de acordo com Scheel-Ybert 2004b). 

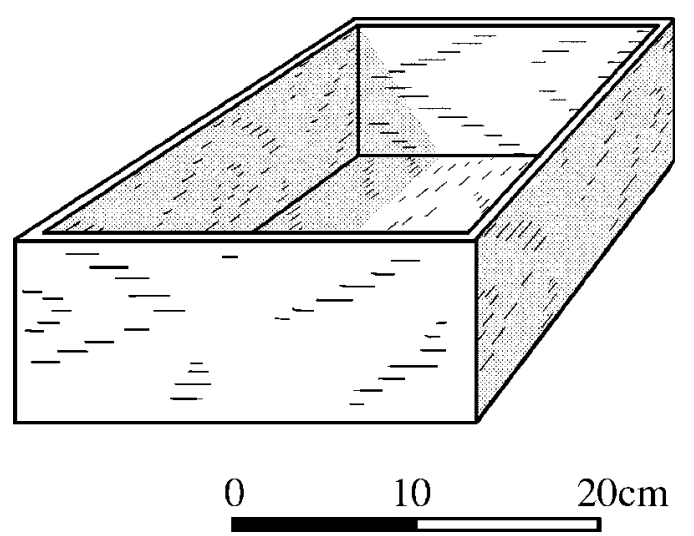

Fig. 8 - Modelo de caixa de madeira, medindo $25 \times 25 \times 10 \mathrm{~cm}$, que pode ser utilizado para coletas zooarqueológicas pelo método da “caixinha”.

A coleta sistemática concomitante à escavação é importante para evitar a seleção, por parte do arqueólogo, de restos faunísticos ou de carvões de maior porte, mais concentrados, ou a coleta preferencial de ossos mais facilmente reconhecíveis pela equipe. A seleção das peças maiores ou mais bem conservadas introduz um elemento de escolha subjetiva que acarretará posteriormente em erros de interpretação. A amostragem sistemática, definida aleatoriamente, permite que sejam coletados todos os vestígios faunísticos e antracológicos contidos na área selecionada, evitando assim distorções na amostragem. No restante das quadras, somente coletar os ossos, conchas ou outros vestígios que sejam particularmente distintivos, assim como os carvões concentrados.

É muito importante, neste tipo de amostragem, sempre evitar "raspar" o sedimento com a colher durante a escavação, especialmente no que se refere ao sedimento que será coletado para antracologia, a fim de não esmagar os carvões, impossibilitando sua análise. Preferencialmente, retirar pequenos blocos de sedimento e colocá-los no balde.

\subsection{Amostragem de perfil}

Idealmente, a amostragem em perfil deve ser feita de acordo com as camadas naturais e/ou culturais de deposição de material. ${ }^{1}$ No entanto, freqüentemente a coleta é facilitada pela definição de níveis artificiais com espessura padrão. Neste caso, recomenda-se sempre identificar as camadas culturais e as feições que porventura ocorram em cada camada artificial e fazer a coleta separadamente. Nunca se deve misturar o material proveniente de sedimentos, depósitos ou feições diferentes numa mesma amostra. Seguir protocolo de coleta (Fig. 9).

É indispensável documentar com detalhes todas as camadas coletadas, descrevendo diferenças de cor, textura do sedimento, densidade da camada, fragmentação e quantidade de material, presença de bioturbação e outros, para que o analista no laboratório possa levar em consideração essas variáveis durante a interpretação dos resultados. Todas estas informações devem constar no formulário de coleta (Fig. 2).

Ao contrário da amostragem sistemática, que contempla toda a superfície do sítio, no caso da amostragem em perfil é recomendável evitar amostrar áreas marginais dos sítios, dando sempre preferência a zonas que possam ser associadas a algum tipo de atividade (habitação, ritual, descarte etc.) ou pelo menos bastante ricas em material arqueológico.

É interessante, sempre que possível, fazer uma amostragem em perfil, especialmente a fim de facilitar a comparação dos resultados com outros sítios já estudados para antracologia (Scheel-Ybert 1999). Da mesma forma, a amostragem em colunas é de grande valia para a zooarqueologia, e utilizada previamente com resultados bastante satisfatórios (Figuti \& Klökler 1996; Klökler 2001).

Para antracologia, sugere-se amostrar um perfil “padrão" seguindo seções de $2 \mathrm{~m}$ de largura por $50 \mathrm{~cm}$ de profundidade, com decapagem de níveis artificiais de $10 \mathrm{~cm}$ de espessura. A fim de se manter constantes a horizontalidade e a espessura dos níveis artificiais neste tipo de amostragem, pode-se utilizar um "guia de amostragem" (Fig. 10), muito simples de construção e de utilização, que facilita a realização de coletas em níveis regulares (Ybert et al. 1997). Este material será posteriormente peneirado ou flotado para separação dos carvões.

(1) Distinguimos aqui níveis artificiais (para os quais é definida uma espessura padrão de $10 \mathrm{~cm}, 20 \mathrm{~cm}$ etc.) de camadas culturais (que correspondem a pisos de ocupação, fundos de cabana, áreas funerárias etc.) e de camadas naturais (depósitos sedimentares de composição diferente). 


\section{PRotocolo de AMOSTRAGem (4)}

\section{Amostragem em perfil}

1. Estabelecer um perfil de $2 \mathrm{~m}$ de largura $\times 0,50 \mathrm{~m}$ de profundidade

2. Amostrar este perfil por níveis artificiais de $10 \mathrm{~cm}$ de espessura. Dentro de cada nível artificial, ter o cuidado de fazer a amostragem de acordo com a estratificação cultural e natural, colocando em sacos separados o material vindo de camadas arqueológicas diferentes e os sedimentos de natureza diferente. Separar também o sedimento de fogueiras, feições ou estruturas arqueológicas (carvões concentrados), mas sempre indicando o nível do perfil a que elas pertencem.

3. A fim de manter constantes a horizontalidade e a espessura dos níveis artificiais, pode-se usar um "guia de amostragem", ou simplesmente marcar os níveis com barbante.

4. Contar o ${ }^{\circ}$ de baldes retirados e anotá-lo na ficha de coleta. Se fôr possível, fazer a pesagem do sedimento de cada balde (sempre lembrar de descontar o peso do balde).

5. Dependendo do caso, colocar o sedimento de cada balde num saco de entulho, aguardando peneiragem ou flotação posterior, ou então peneirar/flotar o conteúdo do balde diretamente. Nunca esquecer de etiquetar o balde ou saco no momento da coleta.

6. Peneirar o sedimento amostrado. Pode ser feita peneiragem ou flotação (malha de 2 ou $4 \mathrm{~mm})$.

7. Todos os carvões, restos faunísticos e restos botânicos retidos pela peneira devem ser coletados.

8. Seguir o "Protocolo de conservação de material biológico".

Fig. 9 - Protocolo de amostragem (4). Roteiro para coleta de restos vegetais e faunísticos, a ser utilizado em casos de amostragem em perfil.

No caso de sambaquis, a amostra zooarqueológica produzida por esta coleta em perfis é excessivamente abundante, e desnecessária. Neste caso, sugere-se que uma fração de apenas 25x25x10 do perfil seja reservada para estudos faunísticos, em cada nível estratigráfico. Pela facilidade de manuseio, sugere-se que esta fração seja coletada através do método de “caixinha” (Klökler 2001). Não se deve, entretanto, em hipótese alguma, negligenciar a triagem das amostras da caixinha também para a antracologia.

\section{Concentração do material}

Coletar o sedimento de cada unidade amostral em baldes, e em seguida peneirá-lo (ou fazer 


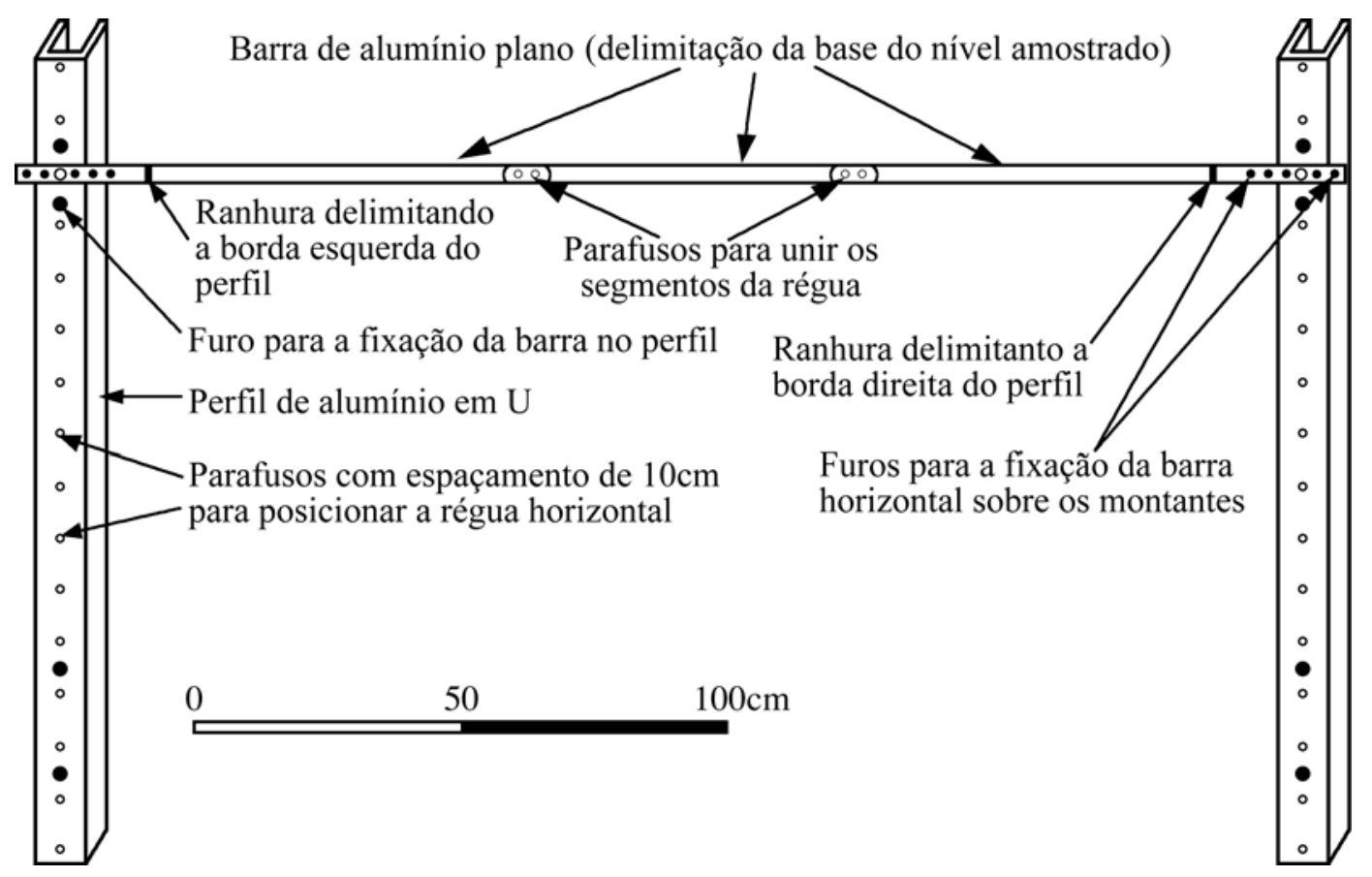

Fig. 10 - Guia de amostragem de perfis sedimentares. Este equipamento pode ser usado a fim de se manter constantes a horizontalidade e a espessura dos níveis artificiais para amostragem de perfil, facilitando a coleta em níveis regulares (adaptado de Ybert et al. 1997).

flotação) para recuperação dos carvões e do material zooarqueológico. É importante verificar se todos os baldes usados na escavação são iguais; caso contrário, estabelecer um tamanho que será usado em todas as amostras. Sempre fazer uma estimativa de volume dos baldes utilizados e anotar nos formulários de coleta (Fig. 2).

Sempre anotar a quantidade de baldes retirada. Além disso, fazer a pesagem do sedimento contido em cada balde, a fim de se ter uma estimativa mais precisa da quantidade de sedimento amostrada, permitindo inferir-se a densidade relativa do material em cada camada arqueológica ou feição.

As amostras de sedimento para zooarqueologia devem ser acompanhadas dos seguintes dados: volume escavado, peso inicial, e peso após peneiramento. $O$ volume escavado é mais adequado que o volume obtido pós-retirada (medido em baldes), pois duas amostras de mesmo volume, de camadas diferentes, podem apresentar diferentes graus de compactação. A partir das informações de volume e peso, pode-se calcular a densidade da camada, que indica o seu grau de compactação. $\mathrm{O}$ peso após peneiramento reflete o grau de fragmentação, que pode ser mais bem discriminado com o uso de peneiras com malhas diferentes.

A conjunção destes índices permite que se comparem amostras diferentes com parâmetros confiáveis, observando as semelhanças e diferenças, e considerando quais são realmente significativas. Deste modo, a análise pode definir se camadas visualmente diferentes o são realmente em seus atributos de compactação, fragmentação e composição.

A malha das peneiras utilizadas deve ser definida rigorosamente. A malha para coleta antracológica nunca pode ser superior a $4 \mathrm{~mm}$. O uso de uma malha de $2 \mathrm{~mm}$ é aconselhado quando os fragmentos são muito pequenos ou se as coletas zooarqueológicas são feitas no mesmo material.

Uma sugestão útil, que facilita muito o trabalho de campo, é a de se pintar a margem das peneiras em cores diferentes (p.ex. azul $=2 \mathrm{~mm}$; amarelo $=$ $4 \mathrm{~mm}$; vermelho $=6 \mathrm{~mm}$ ).

De um modo geral, três métodos de recuperação podem ser utilizados: coleta manual, peneiragem a seco ou com água do sedimento, ou flotação. 
SCHEEL-YBERT, R.; KLÖKLER, D.; GASPAR, M.D.; FIGUTI, L. Proposta de amostragem padronizada para macro-vestígios bioarqueológicos: antracologia, arqueobotânica, zooarqueologia. Rev. do Museu de Arqueologia e Etnologia, São Paulo, 15-16: 139-163, 2005-2006.

\subsection{Coleta manual}

A coleta manual dos carvões ou de vestígios zooarqueológicos é mais indicada para os carvões concentrados, os ossos ou conchas de maior porte e os restos animais estruturados. Ela é útil para identificação de estruturas no campo, por exemplo fogueiras ou estacas queimadas, para dar informações sobre a associação de restos botânicos e zoológicos com outros tipos de vestígios, e também para datação. No entanto, este método não deve ser utilizado como única fonte de amostragem, pois geralmente só leva em conta os fragmentos maiores ou os vestígios animais mais evidentes, resultando inevitavelmente numa amostra distorcida em relação à totalidade do sítio.

\subsection{Peneiragem a seco ou com água do sedi- mento}

A utilização da peneira garante uma melhor amostragem, sendo importante para revelar os carvões e ossos dispersos contidos no sedimento arqueológico. No entanto, é fundamental que todos os fragmentos faunísticos e de carvão retidos pela peneira sejam coletados, pois, também neste caso, a seleção das peças maiores introduziria um elemento de escolha subjetiva que acarreta erros de interpretação.

A peneiragem a seco, relativamente fácil, pois normalmente faz parte da cadeia de atividades na escavação arqueológica, em geral é insuficiente para uma concentração eficaz da amostra antracológica, e também dificulta a identificação de elementos ósseos de pequeno porte. Embora o ideal seja peneirar o sedimento uma única vez, isto nem sempre é possível no campo, devido a limitações técnicas. Por isso pode-se, por exemplo, peneirar o sedimento a seco no campo, com malha de $2 \mathrm{~mm}$ (zooarqueologia) ou 4mm (antracologia), a fim de diminuir a quantidade a ser transportada, e fazer a flotação posteriormente.

A peneiragem com água pode ser feita por imersão parcial das peneiras num tanque, cisterna ou equivalente, ou lavando-se o sedimento da peneira com uma mangueira. A peneiragem com mangueira, muito útil para a zooarqueologia, costuma ser inadequada para a recuperação dos restos vegetais, que podem ser pulverizados pelo jato de água ou pelos instrumentos utilizados para revolver o material (pazinha, colher de pedreiro...).
Quando, por contingências do campo, se opta pela peneiragem com água, é imprescindível abolir a utilização de instrumentos para "ajudar” o sedimento a passar pela peneira, pois isto destrói os carvões e impossibilita sua análise. Mesmo no caso de peneiragem a seco, deve-se evitar esmagar o sedimento contra a peneira, ainda que seja com as mãos, a fim de não destruir os carvões, principalmente quando o sedimento está úmido.

O maior problema envolvido na utilização de peneiras para a amostragem antracológica decorre do enorme volume de material a ser triado, em particular para os níveis ricos em conchas (no caso de sambaquis) ou em cascalho, tornando este método, em geral, lento e pouco produtivo. Para a zooarqueologia, entretanto, o uso de peneiras é extremamente profícuo para a recuperação de ossos e dentes de animais. As peneiras facilitam a visualização de elementos de pequeno porte e diminuem o efeito da seleção de ossos grandes.

\subsection{Flotação}

Este é o método ideal para recuperação dos restos vegetais, pois implica em menor esforço e maior eficiência, além de ser o menos agressivo para o material. A flotação permite a recuperação de material botânico de todas as classes de tamanho preservadas no sedimento, tornando viável a realização de análises quantitativas. Os fragmentos de carvão e outros restos vegetais sendo de pequenas dimensões e muito leves, sua capacidade de flutuação pode ser aproveitada para separá-los do material mais pesado (restos faunísticos, cerâmica etc.).

Esta técnica é baseada na diferença de densidade dos resíduos orgânicos e inorgânicos. Fragmentos carbonizados de madeira, sementes ou tubérculos em geral flutuam, enquanto restos de moluscos, ossos, líticos e cerâmica, são depositados na peneira. Um protocolo de flotação é sugerido na Fig. 11.

Note-se que o processo de flotação é otimizado pela utilização de sedimento seco. Quando a coleta é feita previamente e o sedimento levado ao laboratório para flotar, é indispensável que os sacos plásticos sejam deixados abertos enquanto se aguarda a flotação, pois o acúmulo de umidade no sedimento pode impregnar os carvões e impedir que eles flutuem. 


\section{Protocolo de FLOTAÇão}

1. Colocar o sedimento do balde ou do saco plástico na peneira da célula de flotação cheia de água (usar sempre peneiras com malha de $2 \mathrm{~mm}$ ).

2. Se necessário, revolver o sedimento com as mãos para soltar os carvões, mas sem esmagá-los.

3. Para agilizar o processo, os carvões flutuantes podem ser recolhidos com um coador de plástico; colocá-los delicadamente na peneirinha de saída da célula de flotação.

4. Quando todos os carvões tiverem sido recolhidos, ou tiverem caído na peneirinha externa, retirar a peneira da célula.

5. O sedimento que permaneceu sobre a peneira (refugo de peneira) deve ser sistematicamente triado, a fim de recuperar os fragmentos de carvão que não flutuaram.

6. Quaisquer restos faunísticos que sobrarem na peneira devem ser recuperados, de preferência, coletar todos os vestígios, independente do tamanho, pois mesmo fragmentos mínimos podem conter elementos passíveis de identificação no laboratório.

\section{Manipular os carvões molhados com extremo cuidado, pois eles são muito} frágeis e podem se desagregar à menor pressão.

8. Deixar os carvões ao ar livre para que sequem, longe de uma fonte de calor intensa, a fim de evitar sua fragmentação e deterioração da estrutura anatômica. A melhor forma de secá-los é utilizar cones de papel jornal.

9. Todos os carvões, restos faunísticos e restos botânicos flotados ou retidos pela peneira devem ser coletados.

Fig. 11 - Protocolo de flotação. Roteiro para realização de flotação das amostras de sedimento.

Existem vários modelos de células de flotação, desde o artesanal, baseado na imersão de um balde numa cuba maior contendo água, até os mais elaborados, com assistência mecânica. O modelo de uma célula de flotação desenvolvido no Brasil foi apresentado por Ybert et al. (1997), e uma adaptação do mesmo, com alguns aperfeiçoamentos, é apresentada aqui (Fig. 12). Vários modelos utilizados nos Estados Unidos e na Europa foram apresentados por Pearsall (2000).

Se existir uma fonte de água nas proximidades do sítio, a flotação pode ser feita diretamente no campo. Quando possível, deve-se esvaziar sistematicamente a cuba da célula de flotação após o tratamento de cada amostra, a fim de evitar contaminação entre amostras diferentes, especial- 
SCHEEL-YBERT, R.; KLÖKLER, D.; GASPAR, M.D.; FIGUTI, L. Proposta de amostragem padronizada para macro-vestígios bioarqueológicos: antracologia, arqueobotânica, zooarqueologia. Rev. do Museu de Arqueologia e Etnologia, São Paulo, 15-16: 139-163, 2005-2006.

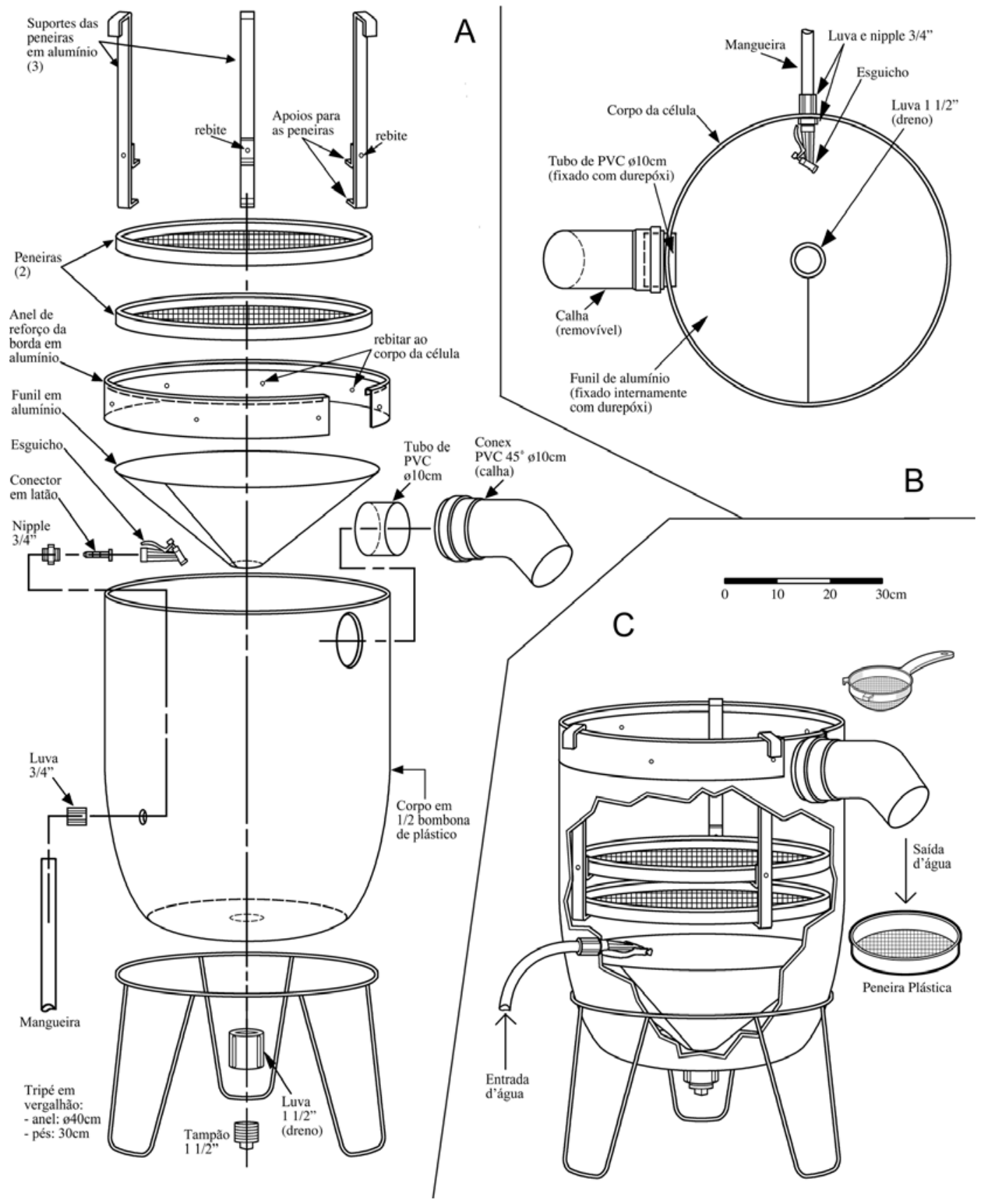

Fig. 12 - Modelo de uma célula de flotação (adaptado de Ybert et al. 1997). A. Vista explodida. B. Vista superior, sem as peneiras, para melhor visualização da instalação hidráulica. C. Vista do conjunto montado. Neste modelo, as peneiras e seus suportes são removíveis. O coador apresentado na parte superior do desenho, à direita, tem por objetivo recolher os carvões flutuantes, a fim de agilizar a operação.

mente quando existe a possibilidade de se fazer uma datação radiocarbônica posterior. É muito importante sempre ter em mente que a flotação e a análise antracológica não prejudicam a datação do 
mesmo fragmento (Vernet et al. 1979), o que é especialmente útil em sítios onde a quantidade de carvões disponível é pequena.

No campo ou no laboratório, o sedimento que permanece sobre a peneira (refugo de peneira) deve ser sistematicamente triado, a fim de recuperar os fragmentos de carvão que não flutuaram. Estes podem ser bastante freqüentes no caso de impregnações calcárias, quando o sedimento está molhado, ou simplesmente devido a diferenças de densidade das madeiras (Scheel-Ybert 2004b).

Secar o material peneirado com água ou submetido a flotação ao ar livre, longe de uma fonte de calor intensa, para evitar sua fragmentação e deterioração da estrutura anatômica. Os carvões e outros restos vegetais podem ser secos em cones de papel jornal (Fig. 13), mas isto deve ser evitado quando se intenciona fazer uma datação posterior. Eles podem também ser deixados para secar na própria peneirinha de saída da flotação ou num saco plástico aberto até que sequem completamente. Neste caso, nunca encher demais o saco plástico, pois um excessivo amontoamento dos fragmentos impede a secagem e provoca perda de material. Em qualquer caso, tomar sempre muito cuidado para evitar contaminação por carvões de outros níveis ou por outros tipos de matéria orgânica atual. Após secagem completa, acondicionar todos os vestígios em sacos plásticos fechados. Todo o material deve ser sempre bem etiquetado.

Nunca manipular os carvões e outros restos vegetais antes de estarem completamente secos, a fim de evitar uma quebra acidental. Da mesma forma, nunca fechar o saco plástico se o material estiver molhado, ou mesmo um pouco úmido, pois ele pode se desagregar, impedindo a análise.

\subsection{Tratamento das amostras de zooarqueologia (no laboratório)}

Após separação dos restos vegetais, pesar todas as amostras de material zooarqueológico, e em seguida peneirá-las, a seco ou com água. Recomenda-se a lavagem das amostras em água corrente com a utilização de uma seqüência de peneiras com malhas de 4 e $2 \mathrm{~mm}$. A utilização de malha dupla facilita a triagem posterior. As diferentes frações granulométricas poderão servir para verificar o teor de fragmentação e compactação dos ossos em cada camada, após pesagem. As malhas estão de acordo com as proposições

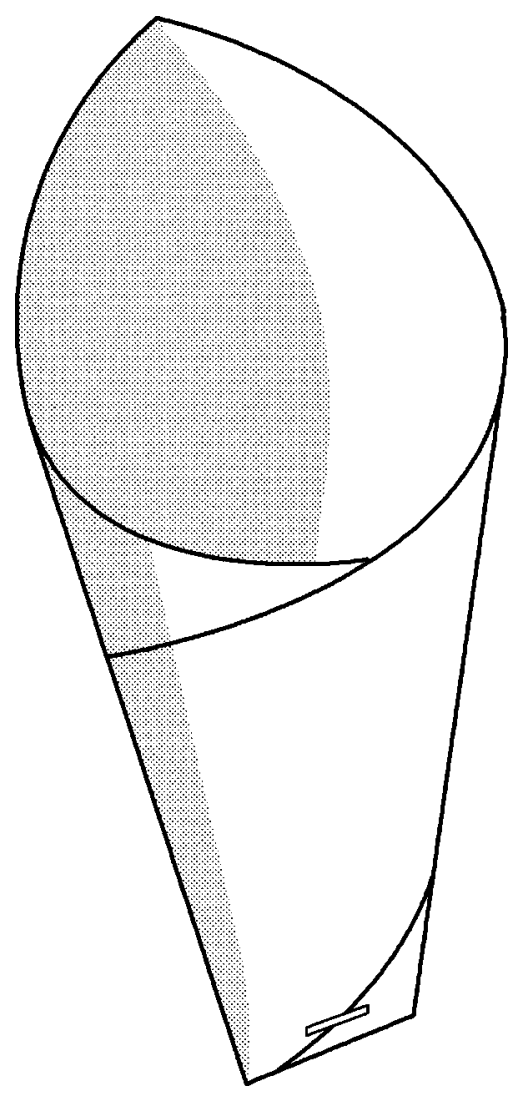

Fig. 13 - Padrão de dobradura dos cones de jornal para secagem de carvões e outros restos botânicos após flotação. Seu tamanho depende do volume de material a ser secado. Normalmente, utiliza-se a metade de uma página de jornal, ou 1/4 da mesma.

apresentadas por outros pesquisadores (Waselkov 1987), que julgam a malha de $2 \mathrm{~mm}$ a que permite a mais fina recuperação de materiais em condições de análise.

Da mesma forma que no caso dos restos vegetais, as amostras zooarqueológicas precisam ser secas naturalmente, sem a utilização de estufas, a fim de evitar a perda súbita de água. Esta última provoca um aumento significativo no grau de fragmentação do material, dificultando a análise.

\section{Discussão}

Um aspecto muito importante a se definir é a escolha da peneira: quanto maior a malha, mais elementos serão perdidos, tanto no que se refere a 
SCHEEL-YBERT, R.; KLÖKLER, D.; GASPAR, M.D.; FIGUTI, L. Proposta de amostragem padronizada para macro-vestígios bioarqueológicos: antracologia, arqueobotânica, zooarqueologia. Rev. do Museu de Arqueologia e Etnologia, São Paulo, 15-16: 139-163, 2005-2006.

carvões, sementes e tubérculos, como também restos ósseos, conchas e outros materiais.

Diversos estudos experimentais alertam que o uso de peneiras maiores que $4 \mathrm{~mm}$ acarretam a perda de grande parte dos ossos de pequenos mamíferos, répteis, peixes e aves (Gordon 1993; Shaffer \& Sanchez 1994), além de provocar uma diminuição significativa na diversidade das amostras vegetais (Chabal 1997). Stewart (1991) notou um aumento de mais de $66 \%$ na quantidade de vestígios faunistícos recuperados com o uso de peneiras de $2 \mathrm{~mm}$ e flotação, em comparação com amostras peneiradas com malha de $5 \mathrm{~mm}$. Em sítios com grande quantidade de animais de pequeno porte (como peixes e anfíbios), o índice de recuperação de elementos pode aumentar em até 97\% em comparação com a peneiragem a seco (Lennox et al. 1986). O uso de peneiras de $2 \mathrm{~mm}$ produzirá uma amostragem ideal para estudos de subsistência, paleoambiente, dieta e outros importantes temas para a arqueologia.

A obtenção de informações a partir dos dados zooarqueológicos será maximizada pela análise de todos os fragmentos retidos na peneira de malha $2 \mathrm{~mm}$. A utilização de uma seqüência de peneiras de diferentes malhas (por exemplo 6mm, $4 \mathrm{~mm}$ e $2 \mathrm{~mm}$ ) facilita a triagem e identificação do material coletado. A utilização exclusiva de peneiras com malha de $4 \mathrm{~mm}$ deve ser evitada em estudos faunísticos, pois grande porcentagem de ossos de peixes e roedores são perdidos durante o processamento, mascarando a realidade das atividades de subsistência das populações estudadas.

No caso da antracologia, em regiões tropicais, costuma-se analisar apenas os fragmentos maiores que $4 \mathrm{~mm}$, pois fragmentos menores em geral não reúnem um conjunto de caracteres anatômicos suficientemente amplo para permitir sua identificação (Scheel-Ybert 2000). Por isso, o uso de peneiras de $4 \mathrm{~mm}$ é suficiente, o que diminuiria o esforço de peneiragem (no campo) e triagem (no laboratório).

A fim de resolver este aparente conflito, aconselhamos que para todas as amostragens conjuntas, utilizem-se peneiras de malha de $2 \mathrm{~mm}$, a fim de que os vestígios coletados possam ser úteis a diversas disciplinas (p.ex. amostragem sistemática do sítio, método de "caixinhas", parte do perfil que servirá para amostragem em antracologia e zooarqueologia, todas as amostras de flotação). No caso de coletas exclusivas para a antracologia, podem-se usar as peneiras de $4 \mathrm{~mm}$ (p.ex. parte do perfil que servirá apenas para a coleta antracológica).

Note-se que é indispensável, em todos os casos, sempre registrar a malha de peneiragem com que o material foi obtido.

\section{Conclusão}

A obtenção de amostras de antracologia, arqueobotânica e zooarqueologia, além de fornecer informações sobre os vegetais e a fauna utilizados pelo grupo que formou o sítio em estudo, produz conhecimentos significativos sobre temas tradicionais tratados pela arqueologia brasileira. Artefatos, marcas de estacas, áreas concrecionadas, depósitos de lixo, entre outras estruturas, podem ser identificados durante a obtenção das amostras e apenas a identificação de tais estruturas já é uma contribuição importante para o entendimento do processo de formação do sítio. Dessa forma, recomenda-se que ao serem identificadas estruturas e artefatos sejam adotados os procedimentos básicos característicos da pesquisa arqueológica, a fim de que se possa construir uma interpretação que integre as diferentes análises.

Por outro lado, os procedimentos sugeridos para a obtenção de amostras de antracologia e zooarqueologia são uma excelente alternativa para se iniciar pesquisa em sítios em bom estado de conservação, onde não existam perfis aparentes. A associação de procedimentos arqueológicos, antracológicos e zooarqueológicos conduz a uma caracterização do sítio bastante completa.

O protocolo aqui desenhado parte do princípio de que o testemunho arqueológico é um bem não renovável e que guarda importantes informações sobre o passado da humanidade. Nesse sentido, visa realizar intervenções do menor porte possível e extrair o máximo de informação relacionado com cada intervenção. Muito embora as reflexões sobre amostragem aqui apresentadas estejam primeiramente voltadas para antracologia/arqueobotânica e zooarqueologia, as intervenções realizadas nos sítios permitem obter informações arqueológicas importantes, tais como as dimensões do pacote arqueológico, sua composição, parâmetros temporais etc., etapa fundamental de toda pesquisa arqueológica.

A sistematização das amostragens antracológicas/ arqueobotânicas e zooarqueológicas busca 
viabilizar a construção de interpretações bem embasadas, através de um conhecimento mais aprofundado das características de cada sítio, assim como produzir um conjunto de dados que conduzam a comparações pertinentes entre diferentes sítios e regiões, especialmente no que se refere à relação das populações pré-históricas com seu meio-ambiente e à dieta alimentar.

\section{Agradecimentos}

Os autores agradecem o apoio financeiro do CNPq (Bolsa PROFIX de Scheel-Ybert; Auxíliopesquisa de Gaspar), FAPERJ ("Cientista do Nosso Estado”, Gaspar), CAPES (Bolsa de Doutorado no Exterior de Klökler) e FAPESP (Projeto Temático coordenado por P.A.D. De
Blasis \& P.C. Giannini, com participação de todos os autores).

Agradecemos igualmente a todos os pesquisadores que aplicaram este protocolo em coletas de campo, nos permitindo testá-lo e aprimorá-lo em vários aspectos. Em particular, o protocolo apresentado foi utilizado durante escavações realizadas no quadro das teses de doutorado de Paula Nishida (“A coisa está preta”, programa de pós-graduação do Museu de Arqueologia e Etnologia, USP, financiamento FAPESP) e de Suely Gleyde Amancio da Silva ("Processo de formação do Sambaqui Ilha das Ostras, no litoral norte da Bahia”, programa de pós-graduação do IGEO/ UFBA, financiamento CNPq).

Os desenhos apresentados nas Figuras 1, $8,10,12$ e 13 foram realizados por William Soares de Borba.

SCHEEL-YBERT, R.; KLÖKLER, D.; GASPAR, M.D.; FIGUTI, L. Proposed sampling standards for bioarchaeological macro-remains: anthracology, archaeobotany, zooarchaeology. Rev. do Museu de Arqueologia e Etnologia, São Paulo, 15-6: 139-163, 2005-2006.

ABSTRACT: This paper calls the attention of Brazilian archaeologists to the importance of bioarchaeological studies. We offer a sampling protocol that can be a useful tool for fulfilling the needs of the bioarchaeological research in the field, leading to a systematic sampling of charcoal, plant, and faunal remains. We propose a sampling strategy that provides comparable data, from diverse sites, on paleoenvironmental conditions, subsistence systems, and interactions between the social and the environmental domains.

UNITERMOS: Archaeology - Anthracology - Zooarchaeology - Sampling Methodology.

\section{Referências bibliográficas}

ALLUÉ,E.

2000 Pollen and charcoal analyses from archaeological sites from the Alto Ribatejo (Portugal). A.R. Cruz; L. Oosterbeek (Eds.) Territórios, mobilidade e povoamento no Alto Ribatejo I. Indústrias e ambientes. Arkeos - Perspectivas em diálogo 9: 37-57. BANDEIRA, D.R.

1992 Mudança na estratégia de subsistência do sítio arqueológico Enseada I: um estudo de caso. Dissertação de Mestrado. Florianópolis, Universidade Federal de Santa Catarina. 127 p.
BERNARD, V:; THIBAUDEAU, C.

2002 Dendroarchaeology and charred wood from the late Neolithic site of Pléchâtel (Brittany, western France). A chronological, palaeoenvironmental and architectural contribution. S. Thiébault (Ed.) Charcoal analysis: Methodological approaches, palaeocological results and wood uses. British Archaeological Reports International Series 1063: 255-259.

BONETTI, C.

1997 Análise do padrão de assentamento dos grupos coletores pescadores do baixo Vale 
SCHEEL-YBERT, R.; KLÖKLER, D.; GASPAR, M.D.; FIGUTI, L. Proposta de amostragem padronizada para macro-vestígios bioarqueológicos: antracologia, arqueobotânica, zooarqueologia. Rev. do Museu de Arqueologia e Etnologia, São Paulo, 15-16: 139-163, 2005-2006.

do Ribeira de Iguape: Levantamento de sítios arqueológicos. Dissertação de CHABAL, L. Mestrado. São Paulo, FFLCH-USP. 153p.

1988 Pourquoi et comment prélever les charbons de bois pour la période antique: les méthodes utilisées sur le site de Lattes (Hérault). Lattara, 1: 187-222.

1997 Forêts et sociétés en Languedoc (Néolithique final, Antiquité tardive). L'anthracologie, méthode et paléoécologie. Documents d'archéologie française, 63: 1-188.

CHERRY,J.F.

1978 Questions of efficiency and integration in assemblage sampling. J.F. Cherry; C. Gamble; S. Shennan (Eds.) Sampling in contemporary British Archaeology. British Archaeological Reports International Series 50: 293-320

CLARK, T.

1998 Assessing room function using unmodified faunal bone: A case study from East-Central Arizona. Kiva, 64 (1): 27-51.

DIAS O.F.; CARVALHO, E.

1983 Um possível foco de domesticação de plantas no Estado do Rio de Janeiro: RJ-JC-64 (sítio Corondó). Boletim do Instituto de Arqueologia Brasileira, sér. Ensaios, 1: 4-18.

DURAND, A.

2002 Elements for a cultural history of wood in Southern France (Xth-XVIth centuries). S. Thiébault (Ed.) Charcoal analysis: Methodological approaches, palaeocological results and wood uses. British Archaeological Reports International Series 1063: 261-266.

FIGUTI, L.

1989 Estudos dos vestígios faunísticos do sambaqui Cosipa-3, Cubatão, São Paulo. Revista de Pré-História, São Paulo, 7: 112-126.

1992 Les sambaquis COSIPA (4200 à 1200 ans $B P):$ étude de la subsistance chez les peuples préhistoriques de pêcheurs-ramasseurs de bivalves de la côte centrale de l'état de São Paulo, Brésil. Tese de Doutorado. Paris, Museum National d'Histoire Naturelle, Institut de Paleontologie Humaine. 212 p.

1993 O homem pré-histórico, o moluso e o sambaqui: considerações sobre a subsistência dos povos sambaquianos. Revista do Museu de Arqueologia e Etnologia, São Paulo, 3: 67-80.

FIGUTI, L.; KLÖKLER, D.

1996 Resultados preliminares dos vestígios zooarqueológicos do sambaqui Espinheiros II (Joinville, SC). Revista do Museu de Arqueologia e Etnologia, São Paulo, 6:169-187.

FISH, S.K.; DE BLASIS, P.A.D.; GASPAR, M.D.; FISH, P.R 1998 Some references for the discussion of complexity among the sambaqui moundbuilders from the Southern shores of Brazil. Revista de Arqueologia Americana, 15: 75-105.
FORD, R.I.

1979 Paleoethnobotany in American Archaeology. Advances in Archaeological Method and Theory, 2: 285-333.

GARCIA, C.R.

1970 Meios de subsistência de duas populações pré-históricas no litoral do Estado de São Paulo. Dissertação de Mestrado. São Paulo: Instituto de Biociências, USP. 47 p.

GASPAR, M.D.; KLÖKLER, D.

2004 Time to die, time to eat: Ritual in shell mounds. Apresentação, 69th Annual Meeting of the Society for American Archaeology, Montreal, março 2004.

GORDON, E.A.

1993 Screen size and differential faunal recovery: A Hawaiian example. Journal of Field Archaeology, 20: $452-460$

GRAYSON, D.K.

1984 Quantitative zooarchaeology: Topics in the analysis of archaeological faunas. Orlando: Academic Press. 202 p.

HILL, E

2000 The contextual analysis of animal interments and ritual practice in Southwestern North America. Kiva. 65 (4): 361-398.

KLÖKLER, D.M.

2001 Construindo ou deixando um sambaqui? Análise de sedimentos de um sambaqui do litoral meridional brasileiro: processos formativos, região de Laguna, SC. Dissertação de mestrado. São Paulo,FFLCH-USP. 164 p.

2003a Vida ritual dos sambaquieiros. Apresentação, XII Congresso da Sociedade de Arqueologia Brasileira, São Paulo, setembro 2003.

2003b Food for body and soul: Ritual and mortuary practices in shell mounds (Laguna, Brazil). Relatório de Atividades, Bolsa de Estudos Tinker, Universidade do Arizona. 15 p.

LENNOX, P.A.; DODD, C.F.; MURPHY, C.R.

1986 The Wiacek Site. A Late Middleport Component Simcoe County, Ontario. Londres: The Ontario Ministry of Transportation and Communications, Environmental Unit, Planning and Design Section.

NISHIDA, $\mathrm{P}$.

2001 Estudo Zooarqueológico do Sítio do Mar Virado (Ubatuba, SP). Dissertação de Mestrado. São Paulo, FFLCH-USP. 167 p

O’CONNOR, T.P.

2000 Archaeology of Animal Bones. Sutton: Stroud. $206 \mathrm{p}$.

PEARSALL, D.M.

2000 Paleoethnobotany: A handbook of procedures. 2nd edition. San Diego: Academic Press, 700 p.

PIANA, E.L.; ESCALERA, J.E.; MITJÁ, A.V.

1998 Lanashuaia: Un Sitio de Canoeros del Siglo Pasado en la Costa Norte del Canal Beagle. In: Desde el País de los Gigantes: Perspectivas Arqueológicas en Patagonia. Tomo II. Río 
SCHEEL-YBERT, R.; KLÖKLER, D.; GASPAR, M.D.; FIGUTI, L. Proposta de amostragem padronizada para macro-vestígios bioarqueológicos: antracologia, arqueobotânica, zooarqueologia. Rev. do Museu de Arqueologia e Etnologia, São Paulo, 15-16: 139-163, 2005-2006.

\author{
Gallegos: Universidad Nacional de la \\ Patagonia Austral, Argentina. \\ POPPER, V.S.; HASTORF, C.A. \\ 1988 Introduction. C.A. Hastorf; V.S. POPPER \\ (Eds.) Current Paleoethnobotany: analytical \\ methods and cultural interpretations of \\ archaeological plant remains. Chicago: The \\ University of Chicago Press: 1-16.
}

POPPER, V.S.

1988 Selecting quantitative measurements in paleoethnobotany. C.A. Hastorf; V.S. Popper (Eds.) Current Paleoethnobotany: analytical methods and cultural interpretations of archaeological plant remains. Chicago: The University of Chicago Press: 53-71.

REITZ, E.; WING, E.

1999 Zooarchaeology. Cambridge: Cambridge University Press. 455 p.

RESENDE, E.M.T.P.; CARDOSO, J.S.

1995-96 Estruturas de armazenamento vegetal: os 'silos' do vale do rio Peruaçu (MG). Coleção Arqueologia, EDIPUCRS, 1 (2): 249-264.

ROUSE, L.J.

2004 Mollusks in the Work Place: Locating Activity Areas Using Fragmentation. Recuperado em 31 de agosto de 2004 através da World Wide Web no endereço: http:// www.scirl.com/papers/jrfrag

RUSSO, M.; QUITMYER, I.

1996 Sedentism in coastal populations of South Florida. E. Reitz; L. Newson; S. Scudder (Eds.) Case Studies in Environmental Archaeology. New York: Plenum Press: 215-233.

SCHEEL, R.; GASPAR, M.D.; YBERT, J.P.

1996 Antracologia, uma nova fonte de informações para a arqueologia brasileira. Revista do Museu de Arqueologia e Etnologia, São Paulo, 6: 3-9.

SCHEEL-YBERT, R.

1998 Stabilité de l'Écosystème sur le Littoral Sud-Est du Brésil à l'Holocène Supérieur (5500-1400 ans BP). Les Pêcheurs-Cueilleurs-Chasseurs et le Milieu Végétal: Apports de l'Anthracologie. Tese de Doutorado. Montpellier: Université Montpellier II, USTL. 3 vol. 520 p.

1999 Paleoambiente e paleoetnologia de populações sambaquieiras do sudeste do Estado do Rio de Janeiro. Revista do Museu de Arqueologia e Etnologia, São Paulo, 9: 43-59.

2000 Vegetation stability in the Southeastern Brazilian coastal area from 5500 to $1400{ }^{14} \mathrm{C}$ yr BP deduced from charcoal analysis. Review of Palaeobotany and Palynology, 110: 111-138.

2001a Man and vegetation in the Southeastern Brazil during the Late Holocene. Journal of Archaeological Science, 28 (5): 471-480.

2001b Vegetation stability in the Brazilian littoral during the late Holocene: anthracological evidence. Revista Pesquisas em Geociências, 28 (2): 315-323.
2002 Evaluation of sample reliability in extant and fossil assemblages. S. Thiébault (Ed.) Charcoal analysis: methodological approaches, palaeoecological results and wood uses. British Archaeological Reports International Series 1063: 9-16.

2003 Relações dos habitantes de sambaquis com o meio ambiente: evidências de manejo de vegetais na costa sul-sudeste do Brasil durante o Holoceno Superior. Atas do IX Congresso da Associação Brasileira de Estudos do Quaternário e II Congresso do Quaternário de Países de Línguas Ibéricas. Cd-rom. Recife, Video Congress. 5 p.

2004a Teoria e métodos em antracologia. 1. Considerações teóricas e perspectivas. Arquivos do Museu Nacional, Rio de Janeiro, 62 (1): 3-14.

2004b Teoria e métodos em antracologia. 2. Técnicas de campo e de laboratório. Arquivos do Museu Nacional, Rio de Janeiro, 62 (4): 343-356.

2005 Teoria e métodos em antracologia. 3. Validade amostral. Arquivos do Museu Nacional, Rio de Janeiro, 63 (2): 207-232.

SCHEEL-YBERT, R.; SOLARI, M.E.; FREITAS, F.DE O.

no prelo Arqueobotânica: Integrando indícios sobre meio ambiente, uso de vegetais e agricultura à arqueologia. Atas do XII Congresso da Sociedade de Arqueologia Brasileira. Cdrom. SAB.

SCHEEL-YBERT, R.; EGGERS, S.; PETRONILHO, C.C.; BOYADJIAN, C.H.; WESOLOWSKI, V.; DE BLASIS, P.A.D.; GASPAR, M.D.

2003 Sistema de subsistência e modo de vida dos construtores de sambaquis: uma abordagem multidisciplinar. Revista de Arqueologia, SAB, 16: 109-137.

SCHOOR, M.H.A.

1975 Abastecimento indígena na área alagadiça lacustre de Rio Grande, Rio Grande do Sul, Brasil. Caderno da ASPES, Associação Santanense Pro Ensino Superior, Santana do Livramento. 115 p.

SHAFFER, B.S. ; SANCHEZ, J.L.J.

1994 Comparison of [!"- and $1 / 4$ "'-mesh recovery of controlled samples of small-to-mediumsized mammals. American Antiquity, 59 (3): 525-530.

STEWART, F.L.

1991 Floating for fauna: Some methodological considerations using the Keffer Site (AkGv14) midden 57 faunal sample. Canadian Journal of Archaeology, 15: 97-115.

TENÓRIO, M.C.

1991 A importância da coleta no advento da agricultura. Tese de Mestrado. Rio de Janeiro: IFCS-UFRJ. $234 \mathrm{p}+$ anexos.

\section{THÉRY-PARISOT, I.}

2001 Économie des combustibles au Paléolithique. Paris: CNRS. $196 \mathrm{p}$. 
SCHEEL-YBERT, R.; KLÖKLER, D.; GASPAR, M.D.; FIGUTI, L. Proposta de amostragem padronizada para macro-vestígios bioarqueológicos: antracologia, arqueobotânica, zooarqueologia. Rev. do Museu de Arqueologia e Etnologia, São Paulo, 15-16: 139-163, 2005-2006.

VERNET, J.-L.; BAZILE, E. : EVIN, J.

1979 Coordination des analyses anthracologiques et des datations absolues sur charbon de bois. Bulletin de la Société de Préhistoire de France, 76 (3): 76-79.

\section{WASELKOV, G.A}

1987 Shellfish gathering and shell-midden archaeology. Advances in Archaeological Method and Theory, 1: 93-209.

WESOLOWSKI, V.

2000 A prática da horticultura entre os construtores de sambaquis e acampamentos litorâneos da região da Baía de São Francisco, Santa Catarina: Uma abordagem bio-antropológica. Tese de Mestrado. São Paulo, FFLCH-USP. 156 p.

WHEELER, A.; JONES, A.K.G.

1989 Fishes. Cambridge: Cambridge University Press. 210 p.

Recebido para publicação em 15 de agosto de 2005.
WILLCOX, G.

2002 Evidence for ancient forest cover and deforestation from charcoal analysis of ten archaeological sites on the Euphrates. S. Thiébault (Ed.) Charcoal analysis: Methodological approaches, palaeocological results and wood uses. British Archaeological Reports International Series, 1063: 141-145.

YBERT, J.P.; SCHEEL, R.; GASPAR, M.D.

1997 Descrição de alguns instrumentos simples utilizados para a coleta e concentração de elementos fósseis de pequenas dimensões de origem arqueológica ou pedológica. Revista do Museu de Arqueologia e Etnologia, São Paulo, 7: 181-189. 